This item was submitted to Loughborough's Research Repository by the author.

Items in Figshare are protected by copyright, with all rights reserved, unless otherwise indicated.

\title{
A full-scale fluvial flood modelling framework based on a high-performance integrated hydrodynamic modelling system (HiPIMS)
}

PLEASE CITE THE PUBLISHED VERSION

https://doi.org/10.1016/j.advwatres.2019.103392

\section{PUBLISHER}

Elsevier BV

VERSION

AM (Accepted Manuscript)

\section{PUBLISHER STATEMENT}

This paper was accepted for publication in the journal Advances in Water Resources and the definitive published version is available at https://doi.org/10.1016/j.advwatres.2019.103392.

\section{LICENCE}

CC BY-NC-ND 4.0

\section{REPOSITORY RECORD}

Xia, Xilin, Qiuhua Liang, and Xiaodong Ming. 2019. "A Full-scale Fluvial Flood Modelling Framework Based on a High-performance Integrated Hydrodynamic Modelling System (hipims)”. Loughborough University. https://hdl.handle.net/2134/9592013.v1. 


\title{
A full-scale fluvial flood modelling framework based on a High- Performance Integrated hydrodynamic Modelling System (HiPIMS)
}

\author{
Xilin $\mathrm{Xia}^{1}$, Qiuhua Liang ${ }^{1 *}$, Xiaodong Ming ${ }^{2}$ \\ 1. School of Architecture, Building and Civil Engineering, Loughborough \\ University, Loughborough, UK
}

2. School of Engineering, Newcastle University, Newcastle upon Tyne, UK

\begin{abstract}
Full-scale fluvial flood modelling over large catchments has traditionally been carried out using coupled hydrological and hydraulic/hydrodynamic models. Such a traditional modelling approach is not well suited for the simulation of extreme floods induced by intense rainfall, which is usually featured with highly transient and dynamic rainfall-runoff and flooding process. This work aims to develop and demonstrate a modelling framework to predict the full-scale process of fluvial flooding from the source (rainfall) to impact (inundation) over a large catchment using a single high-performance hydrodynamic model driven by rainfall inputs. The modelling framework is applied to reproduce the flood event caused by the 2015 Storm Desmond in the $2500 \mathrm{~km}^{2}$ Eden Catchment at $5 \mathrm{~m}$ resolution. Without intensive model calibration, the predicted results compare well with field observations in terms of inundation extent and gauged water levels across the catchment. Sensitivity tests reveal that high-resolution grid is essential for accurate simulation of fluvial flood events using a 2D hydrodynamic model. Accelerated by multiple modern GPUs, the simulation is more than 2.5 times faster than real time although it involves 100 million computational cells inside the computational domain. This work provides a novel and promising approach to assess and forecast at real time the risk of extreme fluvial floods from intense rainfall.
\end{abstract}

\footnotetext{
* Corresponding author: Q.Liang@1boro.ac.uk (Q Liang)
} 


\section{Highlights:}

- A full-scale fluvial flood modelling framework based on a high-performance hydrodynamic model solving the 2D SWEs.

- Successful application to reproduce a storm induced flood in a $2500 \mathrm{~km}^{2}$ catchment at $5 \mathrm{~m}$ resolution.

- High-resolution grid is essential for accurately simulating large-scale fluvial flood using a 2D hydrodynamic model.

Key words: Fluvial flood modelling, high-performance computing, GPU, hydrodynamic model, Godunov-type finite volume method, high-resolution simulation

\section{Introduction}

Flooding has caused over one-third of the global economic loss and been responsible for two-thirds of the people affected by all different types of natural hazards combined, according to the EM-DAT international disaster database [EM-DAT, 2018]. Accounting for more than two thirds of the flood events recorded in the past two decades [EM-DAT, 2018], fluvial flooding as a result of intense or prolonged rainfall poses a great threat to people's life and properties in almost every part of the world. Recent studies (IPCC, 2014) suggest that climate change may lead to more extreme weather events and substantially increase the risk of flooding. It is therefore vitally important to develop effective strategies to manage the risk of fluvial flooding and improve resilience.

To facilitate flood risk assessment and management, numerical modelling has become an indispensable tool. The current practice of full-scale fluvial flood modelling usually involves the use of three types of models to simulate different stages of a flood event: 1) hydrological catchment models (e.g. (Abbott et al., 1986a; Bao et al., 2017; Beven and Freer, 2001; Ewen et al., 2000; Wigmosta et al., 1994)) to represent rainfall-runoff process and predict hydrograph at catchment outlets, 2) 1D river routing models (e.g. (Danish Hydraulic Institute, 2003)) to transfer the flood hydrograph from upstream to downstream, and 3) inundation models (e.g. (Bates and De Roo, 2000; Brufau et al., 2002; Liang, 2010; Telemac software, 2016)) to predict flood extent and impact on floodplains. In this traditional fluvial flood modelling strategy, the hydrological models may be generally classified as conceptual models (e.g. (Bergström, 1995; Liang et al., 1994)) based on the 
principles of water balance, and distributed models solving simplified fluid dynamic equations (e.g. (Abbott et al., 1986b; Beven and Freer, 2001; Wigmosta et al., 1994)). River routing models often solve the 1D St. Venant equations or one of the simplified forms based on kinematic wave and diffusion wave assumptions. Inundation models often solve the shallow water equations (SWEs) or the simplified diffusion-wave equation over two spatial dimensions.

The use of hydrological models and river routing models enables computationally more efficient simulations over large catchments. But hydrological models cannot depict the full dynamic processes of the flood wave generation and propagation. Furthermore, when integrating the three types of models for full-scale fluvial flood modelling, the most common approach is to use the hydrographs estimated by hydrological models as the upstream or lateral inflow boundary conditions to drive river routing models (e.g. [Kim et al., 2012; Laganier et al., 2014; Nguyen et al., 2016; Paiva et al., 2013, 2011]); then the hydrographs translated by the routing models to downstream are used to drive a $2 \mathrm{D}$ hydraulic/hydrodynamic model to predict inundation in floodplains. Such a one-way coupling strategy clearly neglects the dynamic links between different computational domains. However, during an extreme fluvial flood event, the upstream catchment, river networks and floodplains may be dynamically connected through highly transient flow dynamics. Neglecting the actual two-way dynamic flow interactions, such a one-way coupling approach will inevitably introduce extra uncertainties and numerical errors to the simulation results. Therefore, whilst effectively enabling flood simulations over large catchments, this widely applied fluvial flood modelling strategy compromises physical accuracy for computational efficiency and may become problematic when predicting intense rainfall induced transient flooding processes over complex terrains.

Ideally, a single high-resolution hydrodynamic model based on the solution to the full 2D SWEs can be used to simulate the full-scale flood dynamics, from upstream rainfall-runoff to downstream flood inundation across an entire catchment. This approach can effectively resolve flood dynamics across an entire catchment to reduce simulation uncertainties. In the past three decades, full 2D hydrodynamic models have been widely used for flood inundation modelling and occasionally for channel flow routing (e.g. (Begnudelli et al., 2008; Brufau et al., 2002; Hou et al., 2013; Kesserwani and Wang, 2014; Liang et al., 2007; Liang, 2010)). Recently, full 2D hydrodynamic models have also been developed for 
simulating rainfall-runoff induced overland flows (e.g. [Cea and Vázquez-Cendón, 2012; Costabile et al., 2012; Lacaster et al., 2015; Simons et al., 2014; Xia et al., 2017; Yu and Duan, 2017, 2014]). However, due to inhibitive computational cost, no attempt has been reported to use a full 2D hydrodynamic model to simulate, at sufficiently high resolution $(<10 \mathrm{~m})$, the full-scale fluvial flooding process from the upstream rainfall-runoff to the downstream inundation across a large catchment $>1000 \mathrm{~km}^{2}$. Modelling large-scale fluvial flooding process can be fundamentally much more challenging than predicting a storm event across a small catchment. The spatial heterogeneity of large catchments is typically more profound due to the existence of more complicated landscapes and river networks and reliable flood prediction may only be achieved using high-resolution simulations. The conclusions from existing hydrodynamic flood modelling exercises conducted in small catchments may not be directly extendable to large catchments. The question of whether a SWE-based hydrodynamic model is able to accurately predict the complex full-scale flooding process across a large catchment is still unanswered and in need of further research.

The recent advances in high-performance computing technologies have provided a great opportunity to develop and test hydrodynamic models for larger-scale applications. For example, general purpose graphic processing unit (GPU) computing has been demonstrated to be able to accelerate hydraulic models for several orders, in comparison with their counterparts running on traditional CPUs (e.g. (Brodtkorb et al., 2012; Domínguez et al., 2013; Liang et al., 2016; Smith and Liang, 2013; Xia and Liang, 2016)). In particular, highperformance computing on multiple GPUs can go beyond the limitation of physical memory on a single GPU to allow fast simulations involving millions of computational cells (Sætra and Brodtkorb, 2012). With the opportunity provided by the recent advances in high-performance computing technology, this work aims to answer the following research questions:

1. Is a single SWE-based hydrodynamic model able to reliably simulate the full-scale fluvial flooding process induced by intense rainfall over a large catchment of > $1000 \mathrm{~km}^{2}$ ?

2. What are the dominating factors that determine the prediction accuracy of full-scale fluvial flood modelling over large catchments using a 2D SWE-based hydrodynamic model? 
To answer these two research questions, a new modelling framework is developed in this work, based on a High-Performance Integrated hydrodynamic Modelling System (HiPIMS) accelerated by modern GPUs. The new modelling framework enables the simulation of the full-scale fluvial flooding process from rainfall-runoff to inundation at a hyper-resolution of $\leqslant 5 \mathrm{~m}$ in the $2500 \mathrm{~km}^{2}$ Eden Catchment in UK. The rest of the paper is organised as follows: in the following section 2, the new hydrodynamic fluvial flooding modelling framework is introduced; Section 3 presents the necessary details of HiPIMS; Section 4 provides information about the Storm Desmond floods and datasets required by the simulations; Section 5 presents and discusses the simulation results; and finally brief conclusions are drawn in Section 6.

\section{New hydrodynamic fluvial flood modelling framework}

As illustrated in Figure 1, the proposed fluvial flood modelling framework adopts at its core a high-performance integrated hydrodynamic modelling system (HiPIMS) that solves the full 2D SWEs using a finite volume shock-capturing numerical scheme. The whole catchment is adopted as the computational domain and will be first discretised using a uniform grid at a hyper-resolution of 5 10 $\mathrm{m}$. This will allow detailed representation of the catchment topographic features and river networks using high-quality DEM, land-use and river cross-section data, etc. Directly using rainfall as input, HiPIMS calculates the dynamics of surface water moving between grid cells. The Green-Ampt model (Mein and Larson, 1973) is coupled to HiPIMS to estimate soil infiltration. As the catchment topography is described in detail by a high-resolution grid, surface storage will be automatically simulated and captured. Herein, canopy interception and evapotranspiration are assumed to be negligible, which is reasonable for the intense rainfall induced flood events as considered in this work.

Since the current fluvial flood modelling framework does not differentiate the upstream catchment, river and floodplain systems during a simulation, it predicts the full-scale rainfall-runoff and flooding processes and automatically takes into account the flow interactions between the three systems (i.e. upper catchment, river networks and floodplain). This will potentially produce more reliable predictions in comparison with the traditional fluvial flood modelling approach using an integrated model consisting of 
catchment, river routing and inundation modelling components, especially for those highly transient flash floods induced by intense rainfall.

Insert Figure 1 here.

\section{High-Performance Integrated hydrodynamic Modelling System (HiPIMS)}

As the core of the new fluvial flood modelling framework, HiPIMS solves the full 2D SWEs with source/sink terms using a sophisticated shock-capturing numerical scheme and is implemented to run on multiple GPUs to substantially improve its computational efficiency.

\subsection{Governing equations}

The adopted 2D governing equations (i.e. SWEs) may be written in a matrix form as

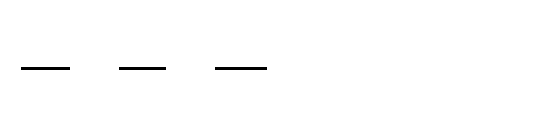

in which $₫$ contains the conserved flow variables, $d$ and $\AA$ are the vectors containing the ? and २-direction fluxes, $\odot^{\circ}, \odot_{\mathrm{W}}$ and $\odot_{\mathrm{M}}$ are the source term vectors respectively representing the runoff, bed slope and friction effects. The vector terms are expressed as

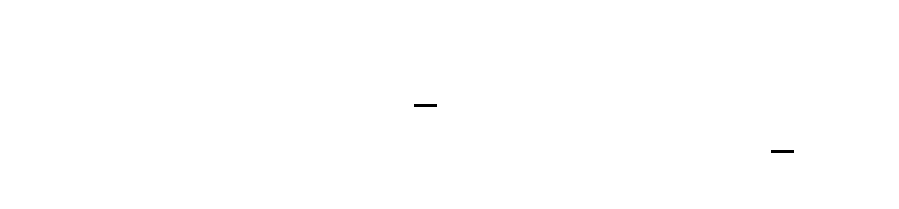

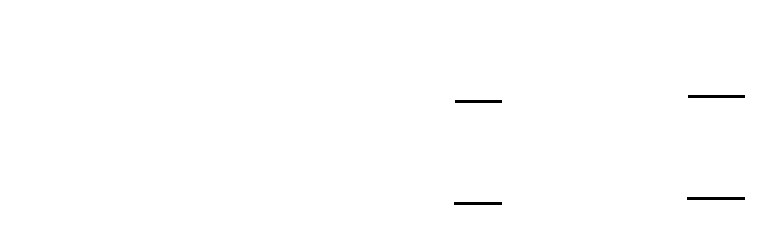

where $h$ is the water depth, I and $\|$ are the depth-averaged velocities in the ? and २directions, $g$ is the acceleration due to gravity, is the rainfall intensity, $\Gamma$ is the infiltration rate, $b$ denotes the bed elevation, 2 is the water density, and $\bar{\sigma}_{\mathrm{W}}$ wand $\bar{\sigma}_{\mathrm{W}_{\omega}}$ are the friction stresses estimated using the Manning formula: 


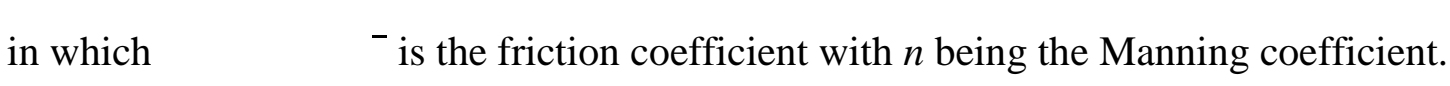

\subsection{Infiltration estimation}

In this work, the infiltration rate is estimated using the Green-Ampt formula given as follows

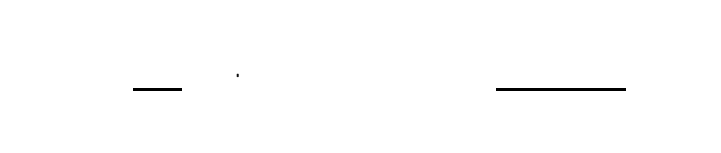

where $\hat{\vartheta}_{\mathrm{q}}$ is the effective hydraulic conductivity; $\bar{\varpi}_{\mathrm{M}}$ is the metric suction head at the wetting front; $\delta_{q}$ is the saturated volumetric water content; $\delta_{d}$ is the initial volumetric water content; constants throughout a simulation. But $\breve{\breve{t}}$ is a variable and needs to be updated at each time step, which may be estimated numerically using a backward Euler method to avoid numerical instability (as it appears at the denominator):

$$
\begin{aligned}
& \simeq \underset{\text { tof }}{\operatorname{tr} q}
\end{aligned}
$$

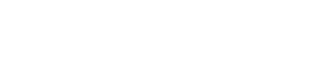

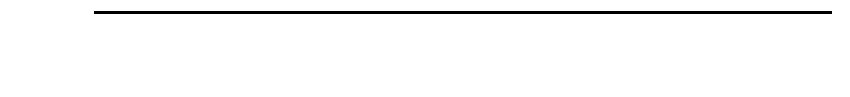

Finally, the discretised form of $\Gamma$ is given by

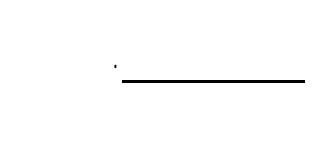

The calculation of infiltration is presented herein for completion but will not be used in the case study in section 5 as infiltration was insignificant and negligible for the specific flood event. 


\subsection{Godunov-type finite volume scheme}

In HiPIMS, the governing SWEs are solved using a Godunov-type finite volume scheme. The surface reconstruction method (SRM) as proposed in (Xia et al., 2017) is implemented to discretise the flux and bed slope terms and the fully implicit method reported by Xia and Liang (2018) is used for handling the stiff friction terms. The resulting model is able to efficiently and stably simulate different types of surface flow hydrodynamics for overland flow, channel hydraulics and flood inundation.

The time-marching scheme for the finite volume method is given as

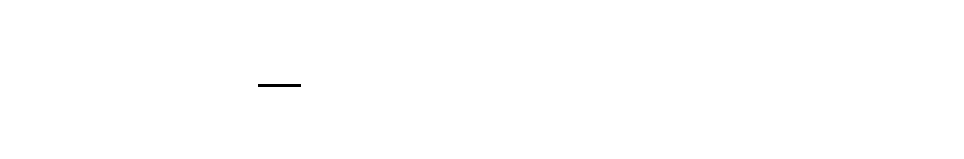

in which the superscript $n$ denotes the time level, subscript $i$ is the cell index, $k$ is the index of cell edges, $\bigcirc_{5}(\mathrm{Q})$ is the flux normal to the cell boundary, ज़ु is the length of cell edge $k$, uois the cell area, and $\mathrm{I}_{z}$ is the time step. In the current numerical scheme, the flux and bed slope terms are explicitly discretised, but the friction terms are calculated using a fully implicit scheme, for which the details can be found in Xia and Liang (2018).

\subsection{Parallel computing on multiple GPUs}

To support high-resolution flood simulation in large catchments, HiPIMS is implemented on multiple GPUs to achieve high-performance computing. GPUs were originally designed for rapid computer visualisation in video games and animations, which is computational demanding as a result of repeating simple computation tasks many times. In recent years it has been realized that the computational power of GPUs can be unleashed to support general-purpose computing, including scientific computing. Programming languages for harnessing GPUs for scientific computing have since been developed, including OpenCL (Khronos Group, 2018), CUDA (NVIDIA Corporation, 2018) and OpenACC (OpenACC Organization, 2018). In this work, the widely used CUDA is adopted to develop HiPIMS.

To support parallel computing across multiple GPUs, a domain decomposition method (Sætra and Brodtkorb, 2012) is adopted and implemented. As illustrated in Figure 2, the whole computational domain is firstly divided into a number of stripe-like sub-domains and each sub-domain contains a similar number of cells. Simulations on these sub-domains 
are carried out separately on different GPUs. Every two neighbouring sub-domains sharing a boundary will have two layers of overlapping cells, namely shared layers. For each of the upper sub-domains, the inner and outer shared layers are respectively denoted as the internal layer and external layer. During a simulation, the values of the flow variables, e.g. depth and unit-width discharges, in the external layer cells of a sub-domain are copied from the corresponding internal layer cells of the neighbouring sub-domain at every time step in order to provide necessary information to complete the required calculation. In this way, all cells except for those in the external layers will have sufficient information to update the flow variables to a new time step. Calculation on the overlapping external layers is unnecessary because they essentially overlap with the corresponding internal layers of neighbouring sub-domains where the values of flow variables are available through normal calculation.

To implement the adopted domain decomposition algorithm in HiPIMS, the C++11 multithreading library is employed, which is part of the standard template library (STL) and can be used together with the CUDA inter-GPU data transfer function to minimize the overhead to facilitate data exchange between GPUs. The procedure of implementing the proposed multi-threading approach for multi-GPU computing is illustrated in Figure 3. At the beginning of a simulation, HiPIMS will launch multiple threads, which by definition are the smallest sequences of programmed instructions that can be managed independently. The number of threads launched is equivalent to the number of available GPUs. Each of the threads will control one of the GPUs, and independently carry out the assigned simulation job for the assigned sub-domain, including reading in inputs, conducting calculations on the GPU, and writing outputs.

Each of the threads is allocated with its own CPU and GPU memories and data exchange occurs at a certain point of each time step. The necessary input data for the simulation on each of the sub-domains is stored separately. When the simulation starts, all necessary input data are read into the CPU memory by each of threads and then copied to the allocated GPU memory. At each time step, the boundary conditions are firstly updated, and then the flow variables are updated in all cells except for those in the external layer (which is unnecessary as explained previously). After all of the flow variables are updated, the values of flow variables in the interior layer cells of each of the sub-domains will be copied from the current GPU memory to the GPU assigned for the neighbouring sub-domain; the flow 
variables will accordingly become the flow variables in the external layer cells of the adjacent sub-domain due to the specific design of the shared layers as illustrated in Figure

2 , providing all necessary flow information for updating flow variables in this neighbouring sub-domain to the next time step. This process will repeat for all of the subdomains and all of the threads will wait until the shared layer flow data are synchronized.

In order to update the time step for the next round of calculation, each of the threads will calculate and return a local time step for its assigned sub-domain. The thread controlling the first GPU will copy all of the local time steps calculated by other threads to its own memory, and then compare and find the minimum time step. This minimum time step will be then copied back to all other threads and used as the global time step for the next iteration of calculation.

The overall calculation procedure will repeat at each time step until the maximum simulation time is reached. At the end of the simulation or during the simulation if necessary, the data on the GPU memory will be copied back to the CPU memory for writing the outputs to files for post-processing.

Insert Figure 2 here.

Insert Figure 3 here.

\section{Case study}

The 2015 Storm Desmond event is simulated in this work to demonstrate the performance of the new hydrodynamic fluvial flooding modelling framework. This section describes the key hydrological and geographical information of the event, and the key data to support the simulations.

\subsection{Description of Storm Desmond in the Eden Catchment}

Storm Desmond was an extratropical cyclone and the fourth named storm during the 20152016 UK and Ireland windstorm seasons. The storm brought heavy rainfall to a large part of the UK on $5^{\text {th }}-6^{\text {th }}$ December. The 48 -hour total rainfall ranged from $174 \mathrm{~mm}$ to 405 $\mathrm{mm}$, which was more than one third of the average annual rainfall in the UK. Such an extreme rainfall event had caused severe floods in north west England, parts of Lancashire and Scottish borders. 
The Eden catchment has been chosen as the study site because Carlisle, the most flooded city during the Storm Desmond event, is located at the downstream of the River Eden. Figure 4 shows a map of the $2500 \mathrm{~km}^{2}$ Eden catchment. There are four major rivers in the catchment, including the River Eden and its three tributaries, i.e. the River Irthing, the River Petteril and the River Caldew. The River Eden merges with the three tributaries as it passes through Carlisle. The time series of the average and median rainfall intensity over the Eden catchment during the Storm Desmond event are plotted in Figure 5. Most of the rainfall happened between 12:00 on $4^{\text {th }}$ December and 12:00 on $6^{\text {th }}$ December 2015.

Insert Figure 4 here.

Insert Figure 5 here.

There are 16 gauges (as marked in Figure 4) located in the four rivers for monitoring water levels and discharges. Most of the gauges are in the downstream part of the catchment, with only a few located upstream. At Sheepmount, a gauge located at the downstream River Eden, the mean flow discharge is measured to be $53.67 \mathrm{~m}^{3} / \mathrm{s}$. During the flooding event, the river level at Sheepmount peaked at $7.8 \mathrm{~m}$, and the flow discharge was estimated to be $1680 \mathrm{~m}^{3} / \mathrm{s}$, which was record-breaking and over 30 times more than the mean flow discharge. It should be noted that the estimated flood discharge is subject to great uncertainty because the river stage was outside the valid range of the established rating curve. Almost the whole city of Carlisle was severely inundated during the event, as evident from the post-event survey shown in Figure 6. A total of 2128 properties were reported to be flooded (Environment Agency, 2018a).

Insert Figure 6 here.

\subsection{Data}

The data for setting up the model includes the Digital Elevation Mode (DEM) over the whole catchment, river cross sections, flood defence locations and heights, land-use data, and rainfall radar records. The DEM at a $5 \mathrm{~m}$ spatial resolution is produced by the UK Ordnance Survey (Ordnance Survey, 2018) and distributed by Edina Digimap (Digimap, 2018). The DEM does not include river bathymetries which are important for hydrodynamic modelling of the flood dynamics in rivers. To improve the accuracy of river flow modelling, the river cross-section data provided by the UK Environment Agency 
(covering the downstream part of River Eden and its three tributaries) are used to correct the DEM. The corrected DEM is further improved by incorporating the locations and heights of flood defences published by the Environmental Agency (Environment Agency, 2018b). The land-use data is extracted from the Land Cover Map 2015 that is available from the Centre for Environmental Data Analysis (CEDA) (CEDA, 2018). In the current simulations, the Manning coefficient is assigned according to different land-use types. The rainfall radar data produced by the UK Met Office NIMROD system at $1 \mathrm{~km}$ spatial resolution and 5 minutes temporal resolution is used to drive the simulations (Met Office, 2003). The data was quality-controlled and corrected using ground-based rain gauge measurements before being released.

Post-event surveyed inundation extents and water level series measured at river gauges are available from the Environment Agency for model validation (Environment Agency, 2018bc). It is noteworthy that the Environment Agency also provides discharge records at some of the river gauges. However, the discharges were not directly measured but estimated from the water level records using established rating curves, which are inevitably subject to high uncertainty during an extreme flooding event. The directly measured water levels are therefore used to compare with the simulation results in this work.

\section{Results and discussion}

A number of simulations have been carried out for the flood event in the whole Eden Catchment. A baseline simulation is presented in 5.1. Based on the baseline simulation, further simulations are run to test the sensitivity of the results to grid resolution and Manning coefficient. Table 1 summarises the key model parameters for the designed simulations.

Insert Table 1 here.

In order to evaluate the performance of the model, two assessment metrics are used, including the root mean squared error (RMSE) and the Nash-Sutcliffe model efficiency coefficient (NSE). The RMSE is calculated using

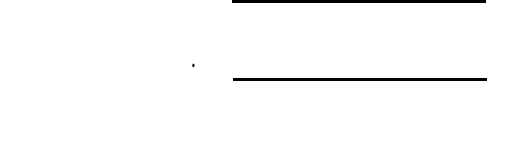


in which $N$ is the total number of time steps $\underset{\Xi}{t_{t}}$ is the observed water depth at time step $n$ and $=\stackrel{t_{t}}{\Theta}$ is the corresponding modelled depth. The NSE is estimated as

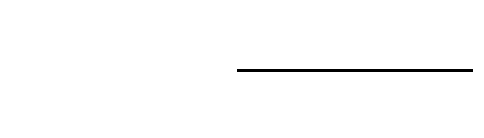

in which $={ }^{5}$ G is the mean observed depth. NSE ranges from ${ }^{\mathrm{N}} \infty$ to $1 . N S E=1$ indicates perfect agreement between the model prediction and observation. $N S E=0$ suggests that the mean observation has been predicted by the model, whereas a negative NSE occurs when the observed mean is a better predictor than the model.

\subsection{The baseline simulation}

The improved $5 \mathrm{~m}$ DEM is used to discretise the $2500 \mathrm{~km}^{2}$ computational domain enclosing the entire Eden catchment, resulting in a uniform grid of 100 million computational cells. In this case study, zero infiltration is assumed due to antecedent rainfall events and fully saturated soil. Without considering infiltration, the model has only one parameter, i.e. the Manning coefficient, to decide. Two sets of Manning coefficient are respectively assigned to the river channels and other areas (e.g. hillslopes and floodplains) for the simulations considered in this work. For this baseline simulation, the Manning coefficients for the river channels and other areas are chosen to be $n_{1}=0.075 \mathrm{sm}^{-1 / 3}$ and $n_{2}=0.055 \mathrm{sm}^{-1 / 3}$, respectively, which are the typical values for river channels and floodplains as suggested in a hydraulic text book (e.g. (Chow, 1959)).

Since the entire catchment of the River Eden is considered in the simulation, the computational domain is only hydrologically linked to the outer domain through a tidal river mouth. But the tidal boundary does not pose any significant influence on the flood event as considered in this work. In addition to a free outflow boundary to represent the river month, there is no need to consider any other boundary conditions for the simulation. Therefore, the simulation is entirely driven by the NIMROD rainfall radar input, which is resampled to $5 \mathrm{~m}$ resolution to provide a rainfall series at each grid cell. To start a simulation, the water depths and discharges in the water bodies inside the computational domain (e.g. rivers and lakes) are also needed as initial conditions. Herein, the antecedent rainfall from 00:00, December $3^{\text {rd }}$ to $12: 00$, December $4^{\text {th }}, 2015$ is used to pre-run the model over a dry bed to produce initial flow conditions for all of the subsequent simulations. 
The simulated flood depth and velocity maps for the city of Carlisle at $t=12,24,36,48$ and $60 \mathrm{hrs}$ since the start of the simulation (i.e. 12:00, $4^{\text {th }}$ December) and the maximum inundation depth are plotted in Figure 7, comparing with the surveyed flood extent as outlined by the blue lines. The rainfall started to spread over the whole catchment at about 18:00, December $4^{\text {th }}, 2015$. Then 6 hours later at $t=12 \mathrm{hrs}$ as shown in Figure $7 \mathrm{a}$, certain low-lying areas have been inundated although significant river bank overflow has still not been experienced. At $t=24 \mathrm{hrs}$ as shown in Figure $7 \mathrm{~b}$, a significant part of the floodplain has been flooded. Since the inundated area is connected to the River Eden, it is inferred that the inundation is mostly caused by overbank flow from the River Eden. Figure 7c presents the inundation map at $t=36 \mathrm{hrs}$, at which the maximum extent has been reached and is compared well with the post-event survey. After the peak has passed, the flood water at the floodplain starts to retreat gradually, as shown by the shrinking inundation maps in Figure 7d\&e for $t=48$ and $60 \mathrm{hrs}$. Finally, the maximum inundation extent is shown in Figure $7 \mathrm{f}$ for the whole simulation, matching satisfactorily the surveyed extent. A number of (numerically) flooded locations are not enclosed by the surveyed flood extent. It is most likely that these areas, most of which are in the rural areas, were not covered by the postevent survey. Overall, the simulated flood extent agrees reasonably well with the postevent survey, confirming the model's capability for predicting intense rainfall induced flooding at a large-scale catchment. The velocity maps are also presented to demonstrate the highly dynamic nature of the flooding process. Before over-bank flow happens, the flood flow is restricted inside river channels and travels rapidly from upstream to downstream, as shown in Figure 7a\&b. But once over-bank flow occurs and the floodplain is inundated, the water course is no longer restricted by the river channels and flood water flows over most of the floodplain and cross the meandering river channels, as shown in Figure $7 c \& d$.

Insert Figure 7 here.

To highlight the importance of depicting flood dynamics across the entire catchment, the flood depth and velocities are also plotted for midstream and upstream sections of the River Eden in Figure 8 and Figure 9, which effectively show that the midstream and upstream parts of the catchment have also been severely flooded. The results confirm that different parts of the catchment, including the river networks and floodplains may be dynamically connected during an extreme flood event to collectively influence the whole flooding 
process. The dynamic river-floodplain interactions in both upstream and downstream clearly cannot be captured by the traditional hydrological-hydraulic coupled modelling approaches. Therefore, it is necessary to apply a fully hydrodynamic model across the entire catchment to reliably predict transient flooding process induced by intense rainfall.

Insert Figure 8 here.

Insert Figure 9 here.

In Figure 10, the predicted water level hydrographs are compared with the observations available at the 16 river gauges in the Eden catchment (as listed in Table 2). The patterns of the water level hydrographs vary across different locations. For the downstream gauges such as 'Sheepmount', 'Sands Centre', and 'Linstock', the water level gradually rises to its peak and then decreases gradually at a similar rate, forming hydrographs of roughly a triangular shape. But for those upstream gauges such as 'Kirkby Stephen', 'Great Musgrave Bridge' and 'Temple Sowerby', the water level rises sharply, followed by small fluctuations, before it decreases sharply and returns to the base flow level. The variation of hydrograph patterns and arrival time of peaks across different locations of the catchment has been well captured by the numerical simulation, demonstrating that the proposed model is able to depict the flood dynamics across the entire catchment.

Insert Figure 10 here.

To provide quantitative assessment of the simulation results, RMSE and NSE are calculated and summarised in Table 3 and Table 4. As mentioned, the rivers gauges are distributed unevenly across the catchment with most of the gauges located in the downstream areas. Therefore, the overall mean of RMSE and NSE may be biased by the downstream gauges and do not reflect the simulation accuracy across different parts of the catchment. Instead, we analyse the RMSEs and NSEs in groups and the river gauges are divided into four groups as listed in Table 2, based on two criteria: 1) whether they are located in River Eden or in the tributaries; and 2) whether they are located downstream or upstream. The mean NSEs and RMSEs are calculated for the numerical results obtained for each group of the river gauges are also presented in Table 3 and Table 4. It should be noted that major deviation from the observations can be found in the prediction for the gauge at Great Musgrave Bridge. This is likely caused by a localised vertical error existing in the DEM because the overall profiles of the measured and predicted water level hydrographs are remarkably 
similar but there exists a large shift in magnitude. The result at this gauge is therefore excluded from further analysis. Herein, we are particularly interested in the RMSEs and NSEs at the downstream gauges of River Eden, i.e. the gauges in group 1, as the water levels at these gauges are the primary indicator of the downstream inundation in Carlisle. For these four gauges, the mean NSE is 0.89 and the mean RMSE is $0.53 \mathrm{~m}$, which is about $10 \%$ of the average increase of water level from the base flow to the peak. Considering the potential large uncertainty from the radar rainfall data that drives the simulation (e.g. Hasan et al., 2016), both of the mean NSE and RMSE are acceptable and indicate good performance of the model.

For the upstream gauges and those gauges located on the tributaries, smaller mean NSEs are returned, indicating less accurate predictions. According to the mean NSEs, the least accurate results are obtained for the upstream gauges on the tributaries. The different results between the downstream and upstream gauges may be explained by the different precision of the topographic data. Surveyed river cross-section data has been embedded into the downstream DEM to better represent the channel geometries while no cross-section data is available for the upstream regions to improve the DEM. The difference in channel width may explain the difference between the results obtained in the Eden gauges and tributary gauges. The tributary channels are much narrower and the predicted water levels may be more sensitive to the error of channel bathymetries.

As a summary, the accuracy of the simulation results varies across the catchment when comparing with gauge measurements at different locations due to a number of reasons as explained above. The overall accuracy of the results, qualitatively and quantitatively, is considered to be reasonable for such a challenging large-scale simulation of the rainfallflooding process. And the simulation has successfully reproduced the flooding process and inundation extent in the downstream city Carlisle.

Insert Table 2 here.

\subsection{Model sensitivity}

The Manning coefficient and the grid resolution are the two key model parameters to consider when setting up HiPIMS for flood modelling. Further simulations are hence carried out using the new HiPIMS based fluvial flood modelling framework to test the sensitivity of the simulation results to these parameters. 


\subsubsection{Model sensitivity to Manning coefficient}

To test the model sensitivity to the Manning coefficient, the model set up for the baseline simulation is used to run four further simulations by varying the Manning coefficients in both of the land areas and river channels, i.e. $\left(n_{1}=0.075 \mathrm{sm}^{-1 / 3}, n_{2}=0.035 \mathrm{sm}^{-1 / 3}\right),\left(n_{1}=\right.$ $\left.0.075 \mathrm{sm}^{-1 / 3}, n_{2}=0.075 \mathrm{sm}^{-1 / 3}\right),\left(n_{1}=0.095 \mathrm{sm}^{-1 / 3}, n_{2}=0.055 \mathrm{sm}^{-1 / 3}\right)$ and $\left(n_{1}=0.055 \mathrm{sm}^{-1 / 3}\right.$, $n_{2}=0.055 \mathrm{sm}^{-1 / 3}$ ). The maps of maximum inundation depth from the baseline simulation and the four new simulations are plotted and compared in Figure 11. The maximum flood extents are generally similar for all five simulations, except for the noticeable differences appeared at the upstream areas. Upstream of Great Corby, simulations with smaller river channel Manning coefficient ( $\left.n_{2}\right)$ predict some vacuum areas (i.e. no inundation). On the other hand, the simulations with the same Manning coefficient $\left(n_{2}\right)$ for river channels but different Manning coefficients elsewhere $\left(n_{1}\right)$ provide very similar results.

Inset Figure 11 here.

The difference between the five simulations may be seen more clearly by looking at the water levels at the 16 gauges as plotted in Figure 12. As evidenced from the results, varying $n_{1}$ and $n_{2}$ may both affect the predicted time histories of water level, but in different ways. Increasing $n_{2}$ accelerates the rising water levels, which subsequently increases the peak water levels and slows down falling limp of the water level hydrograph. On the other hand, increasing $n_{1}$ slows down both the rising and falling limps of water level profiles, and increases the peak water levels. Physically the values of Manning coefficient in the river channels affects the speed of draining water out of the catchment. As a consequence, increasing $n_{2}$ causes more water retained in the river channels, leading to accelerated rising limps, decelerated falling limps and higher flood peaks. The values of Manning coefficient on the hillslopes influence the velocity of overland flows, i.e. the speed of feeding water into the river channels. Larger $n_{1}$ delays the water draining into river channels, leading to the subsequent delayed rising and falling limps of temporal water level profiles in the river channels. It is also evident from the results that the influence of $n_{2}$ on the water level profiles is more significant than the influence posed by $n_{1}$. As a summary, the simulation results seem to be more sensitive to the choice of Manning coefficient for the river channels $\left(n_{2}\right)$ than for the other parts of the catchment $\left(n_{1}\right)$. 
Overall, the simulation results are consistent for different Manning coefficients and as expected. The inundation extent at the downstream region is not very sensitive whilst the water levels seem to be slightly more sensitive to the change of Manning coefficient. The present hydrodynamic fluvial flood modelling framework essentially includes only one physical parameter, i.e. the Manning coefficient, when infiltration is not considered. The values of the Manning coefficient used in the simulations are aligned with those standard values suggested in hydraulics textbooks. Therefore, the effort as required for model calibration is minimum for the proposed hydrodynamic fluvial flood modelling framework.

Insert Figure 12 here.

\subsubsection{Model sensitivity to grid resolution}

When applying a hydrodynamic model for large-scale flood simulation, it is essentially to understand how grid resolution may affect the simulation results. Further simulations are therefore run using DEMs of different resolutions, i.e. $10 \mathrm{~m}, 20 \mathrm{~m}$ and $40 \mathrm{~m}$. Figure 13 compares the four maximum inundation maps produced at different resolutions. Compared with the $5 \mathrm{~m}$ inundation map which most closely matches the post event observations, both of the $10 \mathrm{~m}$ and $20 \mathrm{~m}$ simulations predicts much more serious inundation to the left bank of the gauge Denton Holme (bottom left in the graphs). The inundated area is connected to the river channel and caused by overbank flow, which did not happen in reality. The inaccurate predictions of inundation near to Denton Holme by the $10 \mathrm{~m}$ and $20 \mathrm{~m}$ simulations are a direct result of the insufficient resolution of river geometries and flood defences of the River Caldew. As clearly illustrated in Figure 14, the fine details of the river channel geometries and the flood defences are well represented on the $5 \mathrm{~m}$ DEM but not on the $10 \mathrm{~m}$ and $20 \mathrm{~m}$ DEMs. Particularly, the river course has clearly become disconnected and the flood defence is barely recognisable on the $20 \mathrm{~m}$ resolution DEM, which will obviously lead to inaccurate prediction as observed. Despite the major difference in the predicted inundation near to Denton Holme, the overall flood extent produced by the three simulations are similar and consistent because the flood event is predominantly driven by the overbank flows from the River Eden, which is well represented on all three DEMs. On the $40 \mathrm{~m}$ DEM, the simulation predicts a flood extent deviating further from the observation. Poor representation of topographic features, river courses and flood defences alter the flood routes and subsequently provides unsatisfactory inundation prediction. 
The above conclusion is further confirmed in Figure 15, in which the time histories of water level predicted by the four different simulations are compared with the available gauge observations. The simulation on the $40 \mathrm{~m}$ DEM clearly predicts unacceptable results. The corresponding NSEs and RMSEs calculated for the different simulations are listed in Table 3 and Table 4. The mean NSEs calculated from the coarse-resolution simulation results (10 $\mathrm{m}, 20 \mathrm{~m}$ and $40 \mathrm{~m}$ ) are all smaller than the one obtained for the baseline simulation and the mean RMSEs are consistently larger. From the results, it is evident that reliable hydrodynamic prediction of fluvial flood dynamics and inundation can only be achieved when the adopted DEM and computational grid are at sufficiently high resolution to accurately represent the details of topographic features and river geometries.

Insert Figure 13 here.

Insert Figure 14 here.

Insert Figure 15 here.

Insert Table 3 here.

Insert Table 4 here.

\subsection{Computational efficiency}

All of the simulations are run on a GPU server with 8 Nvidia Tesla K80 GPUs and the runtimes as required are summarised in Table 5. All of the simulations are much faster than real time. Even for the $5 \mathrm{~m}$ simulation that involves 100 million cells it is still completed at 2.5 times faster than real time, which effectively demonstrates the potential of the current hydrodynamic fluvial flood modelling framework (HiPIMS) for efficient flood simulation and real-time forecasting.

Insert Table 5 here.

\section{Conclusions}

This paper presents a novel fluvial flooding modelling framework for the simulation of the entire flooding process from the source (rainfall) to impact (inundation) using a single hydrodynamic model. The adopted hydrodynamic model (HiPIMS) solves the full 2D SWEs using a carefully designed shock-capturing Godunov-type finite volume numerical 
scheme to reliably simulate the full-scale flooding processes (i.e. rainfall-runoff, overland flow, channel hydraulics and inundation) induced by intense rainfall. The flood modelling framework is further implemented on multiple GPUs using a domain decomposition method to achieve unprecedented high computational speed for high-resolution flood simulation over a large domain/catchment.

The new fluvial flood modelling framework is applied to predict an extreme flood event caused by the 2015 Storm Desmond in the $2500 \mathrm{~km}^{2}$ Eden catchment in the UK. At $5 \mathrm{~m}$ spatial resolution, the simulation successfully reproduces the event with results comparing favourably with the available observations in terms of both flood extent and gauged water level. Involving 100 million cells, the simulation is over 2.5 times faster than real time on a multi-GPU server, effectively demonstrate the potential of the new flood modelling framework for efficient flood risk assessment and real-time flood forecasting.

Further simulations have been carried out to test the sensitivity of the numerical results to different Manning coefficients and grid resolutions. Quantitative analysis of the simulation results indicates that the model is slightly more sensitive to the choice of Manning coefficient in the river channels than in the hillslopes and floodplains. But the overall simulation results are consistent. The simulated flood extent at the downstream is not very sensitive whilst the water levels at the gauges are slightly more sensitive to the choice of Manning coefficients. For the simulation of a highly dynamic flood event as considered in this work, reliable predictions can be obtained by adjusting the standard values of Manning coefficient as suggested in hydraulics textbooks, removing the substantial effort for model calibration. On the other hand, the simulation results are found to be highly sensitive to the grid resolution and high-resolution simulations that can represent the catchment topographic features and river geometries in sufficient detail are necessary to accurately predict the full-scale transient flooding processes.

\section{Acknowledgment}

This work is partly funded by the NERC funded SINATRA/TENDERLY projects (NE/K008781/1), Flood-PREPARED project (NE/P017134/1), WeACT project (NE/S005919/1), FUTURE-DRAINAGE project (NE/S016678/1) and River basins as living laboratories project (NE/S012427/1). 


\section{References}

Abbott, M.B., Bathurst, J.C., Cunge, J.A., O’Connell, P.E., Rasmussen, J., 1986a. An introduction to the European Hydrological System — Systeme Hydrologique Europeen, "SHE", 1: History and philosophy of a physically-based, distributed modelling system. J. Hydrol. 87, 45-59. https://doi.org/https://doi.org/10.1016/00221694(86)90114-9

Abbott, M.B., Bathurst, J.C., Cunge, J.A., O 'connell, P.E., Rasmussen, J., 1986b. An introduction to the European Hydrological System - Systeme Hydrologique Europeen, "SHE', 2: Structure of a physically-based, distributed modelling system. J. Hydrol. 87, 61-773. https://doi.org/10.1016/0022-1694(86)90115-0

Bao, H., Wang, L., Zhang, K., Li, Z., 2017. Application of a developed distributed hydrological model based on the mixed runoff generation model and 2D kinematic wave flow routing model for better flood forecasting. Atmos. Sci. Lett. 18, 284-293. https://doi.org/10.1002/asl.754

Bates, P.D., De Roo, A.P.J., 2000. A simple raster-based model for flood inundation simulation. J. Hydrol. 236, 54-77. https://doi.org/10.1016/S0022-1694(00)00278-X

Begnudelli, L., Sanders, B.F., Bradford, S.F., 2008. Adaptive Godunov-Based Model for Flood Simulation. J. Hydraul. Eng. 134, 714-725. https://doi.org/10.1061/(ASCE)0733-9429(2008)134:6(714)

Bergström, S., 1995. The HBV model, in: Singh, V.. (Ed.), Computer Models of Watershed Hydrology. Water Resources Publications, Highlands Ranch, Colorado.

Beven, K., Freer, J., 2001. A dynamic TOPMODEL. Hydrol. Process. 15, 1993-2011. https://doi.org/10.1002/hyp.252

Brodtkorb, A.R., Sætra, M.L., Altinakar, M., 2012. Efficient shallow water simulations on GPUs: Implementation, visualization, verification, and validation. Comput. Fluids 55, 1-12. https://doi.org/10.1016/j.compfluid.2011.10.012

Brufau, P., Vázquez-Cendón, M.E., García-Navarro, P., 2002. A numerical model for the flooding and drying of irregular domains. Int. J. Numer. Methods Fluids 39, $247-$ 275. https://doi.org/10.1002/fld.285

Cea, L., Vázquez-Cendón, M.E., 2012. Unstructured finite volume discretisation of bed friction and convective flux in solute transport models linked to the shallow water equations. J. Comput. Phys. 231, 3317-3339. https://doi.org/10.1016/j.jcp.2012.01.007 
CEDA, 2018. Land Cover Map 2015 [WWW Document]. URL https://catalogue.ceh.ac.uk/documents/0255c014-1630-4c2f-bc05-48a6400dd045

Chow, V.T., 1959. Open Channel Hydraulics. McGraw-Hill B. Co. https://doi.org/ISBN 07-010776-9

Costabile, P., Costanzo, C., Macchione, F., 2012. Comparative analysis of overland flow models using finite volume schemes. J. Hydroinformatics 14, 122. https://doi.org/10.2166/hydro.2011.077

CRED, 2018. EM-DAT: The international disaster database [WWW Document]. URL http://www.emdat.be

Danish Hydraulic Institute, 2003. MIKE11 A modelling system for rivers and channels User Manual.

Digimap, 2018. Edina's Digimap [WWW Document]. URL https://digimap.edina.ac.uk Domínguez, J.M., Crespo, A.J.C., Valdez-Balderas, D., Rogers, B.D., Gómez-Gesteira, M., 2013. New multi-GPU implementation for smoothed particle hydrodynamics on heterogeneous clusters. Comput. Phys. Commun. 184, 1848-1860. https://doi.org/http://dx.doi.org/10.1016/j.cpc.2013.03.008

Environment Agency, 2018a. Carlisle flood investigation report [WWW Document]. URL https://www.cumbria.gov.uk/eLibrary/Content/Internet/536/6181/42494151257.pdf Environment Agency, 2018b. Spatial Flood Defences (including standardised attributes) [WWW Document]. URL https://data.gov.uk/dataset/spatial-flood-defencesincluding-standardised-attributes

Environment Agency, 2018c. Historic FLood Map [WWW Document]. https://doi.org/https://data.gov.uk/dataset/historic-flood-map1

Ewen, J., Parkin, G., O’Connell, P.E., 2000. Shetran : Distributed River B Asin F Low Modeling System. J. Hydrol. Eng. 5, 250-258.

Hasan, M.M., Sharma, A., Mariethoz, G., Johnson, F., Seed, A., 2016. Improving radar rainfall estimation by merging point rainfall measurements within a model combination framework. Adv. Water Resour. 97, 205-218. https://doi.org/10.1016/j.advwatres.2016.09.011

Hou, J., Liang, Q., Simons, F., Hinkelmann, R., 2013. A 2D well-balanced shallow flow model for unstructured grids with novel slope source term treatment. Adv. Water Resour. 52, 107-131. https://doi.org/10.1016/j.advwatres.2012.08.003

IPCC, 2014. Climate Change 2014: Synthesis Report. Contribution of Working Groups I, 
II and III to the Fifth Assessment Report of the Intergovernmental Panel on Climate Change [Core Writing Team, R.K. Pachauri and L.A. Meyer (eds.)]. Geneva, Switzerland.

Kesserwani, G., Wang, Y., 2014. Discontinuous galerkin flood model formulation: Luxury or necessity? Water Resour. Res. 50, 6522-6541.

https://doi.org/10.1002/2013WR014906

Khronos Group, 2018. Open CL Overview [WWW Document]. URL https://www.khronos.org/opencl/

Kim, J., Warnock, A., Ivanov, V.Y., Katopodes, N.D., 2012. Coupled modeling of hydrologic and hydrodynamic processes including overland and channel flow. Adv. Water Resour. 37, 104-126. https://doi.org/10.1016/j.advwatres.2011.11.009

Lacaster, A., Morales-Hernandez, M., Murillo, J., Garcia-Navarro, P., 2015. GPU implementation of the 2D shallow water equations for the simulation of rainfall/runoff events. Environ. Earth Sci. 74, 7295-7305. https://doi.org/10.1007/s12665-015-4215-z

Laganier, O., Ayral, P.A., Salze, D., Sauvagnargues, S., 2014. A coupling of hydrologic and hydraulic models appropriate for the fast floods of the Gardon River basin (France). Nat. Hazards Earth Syst. Sci. 14, 2899-2920. https://doi.org/10.5194/nhess-14-2899-2014

Liang, D., Lin, B., Falconer, R.A., 2007. Simulation of rapidly varying flow using an efficient TVD-MacCormack scheme. Int. J. Numer. Methods Fluids 53, 811-826. https://doi.org/10.1002/fld.1305

Liang, Q., 2010. Flood simulation using a well-balanced shallow flow model. J. Hydraul. Eng. 136, 669-675.

Liang, Q., Xia, X., Hou, J., 2016. Catchment-scale High-resolution Flash Flood Simulation Using the GPU-based Technology, in: Procedia Engineering. https://doi.org/10.1016/j.proeng.2016.07.585

Liang, X., Lettenmaier, D.P., Wood, E.F., Burges, S.J., 1994. A simple hydrologically based model of land surface water and energy fluxes for general circulation models. J. Geophys. Res. Atmos. 99, 14415-14428. https://doi.org/10.1029/94JD00483 Mein, R.G., Larson, C.L., 1973. Modeling infiltration during a steady rain. Water Resour. Res. 9, 384-394. https://doi.org/10.1029/WR009i002p00384

Met Office, 2003. Met Office Rain Radar Data from the NIMROD System [WWW Document]. URL 
http://catalogue.ceda.ac.uk/uuid/82adec1f896af6169112d09cc1174499

Nguyen, P., Thorstensen, A., Sorooshian, S., Hsu, K., AghaKouchak, A., Sanders, B.,

Koren, V., Cui, Z., Smith, M., 2016. A high resolution coupled hydrologic-hydraulic model (HiResFlood-UCI) for flash flood modeling. J. Hydrol. 541, 401-420.

https://doi.org/10.1016/j.jhydrol.2015.10.047

NVIDIA Corporation, 2018. About CUDA [WWW Document]. URL

https://developer.nvidia.com/about-cuda

OpenACC Organization, 2018. About OpenACC [WWW Document]. URL

https://www.openacc.org

Ordnance Survey, 2018. OS Terrain 5 [WWW Document]. URL

https://www.ordnancesurvey.co.uk/business-and-government/products/os-terrain5.html

Paiva, R.C.D., Buarque, D.C., Collischonn, W., Bonnet, M., Frappart, F., Calmant, S., Mendes, C.A.B., 2013. Large-scale hydrologic and hydrodynamic modeling of the Amazon River basin. Water Resour. Res. 49, 1226-1243.

https://doi.org/10.1002/wrcr.20067

Paiva, R.C.D., Collischonn, W., Tucci, C.E.M., 2011. Large scale hydrologic and hydrodynamic modeling using limited data and a GIS based approach. J. Hydrol. 406, 170-181. https://doi.org/10.1016/j.jhydrol.2011.06.007

Sætra, M.L., Brodtkorb, A.R., 2012. Shallow Water Simulations on Multiple GPUs, in: Jónasson, K. (Ed.), PARA2010: Applied Parallel and Scientific Computing. Springer Berlin Heidelberg, Berlin, Heidelberg, pp. 56-66.

Simons, F., Busse, T., Hou, J., Özgen, I., Hinkelmann, R., 2014. A model for overland flow and associated processes within the Hydroinformatics Modelling System. J. Hydroinformatics 16, 375-391.

Smith, L., Liang, Q., 2013. Towards a generalised GPU/CPU shallow-flow modelling tool. Comput. Fluids 88, 17-20.

Telemac software, 2016. Telemac 2D [WWW Document]. URL http://www.opentelemac.org/index.php/modules-list/17-telemac-2d-presentation

Wigmosta, M.S., Vail, L.W., Lettenmaier, D.P., 1994. A distributed hydrologyvegetation model for complex terrain. Water Resour. Res. 30, 1665-1679. https://doi.org/10.1029/94WR00436

Xia, X., Liang, Q., 2018. A new efficient implicit scheme for discretising the stiff friction terms in the shallow water equations. Adv. Water Resour. 117, 87-97. 
https://doi.org/10.1016/j.advwatres.2018.05.004

Xia, X., Liang, Q., 2016. A GPU-accelerated smoothed particle hydrodynamics (SPH) model for the shallow water equations. Environ. Model. Softw. 75, 28-43. https://doi.org/10.1016/j.envsoft.2015.10.002

Xia, X., Liang, Q., Ming, X., Hou, J., 2017. An efficient and stable hydrodynamic model with novel source term discretisation schemes for overland flow and flood simulations. Water Resour. Res. 53, 3730-3759.

https://doi.org/10.1002/2016WR020055

Yu, C., Duan, J., 2017. Simulation of Surface Runoff Using Hydrodynamic Model. J. Hydrol. Eng. 1-12. https://doi.org/10.1061/(ASCE)HE.1943-5584.0001497.

Yu, C., Duan, J., 2014. Two-Dimensional Hydrodynamic Model for Surface-Flow Routing. J. Hydraul. Eng. 140, 1-13. https://doi.org/10.1061/(ASCE)HY.19437900.0000913. 


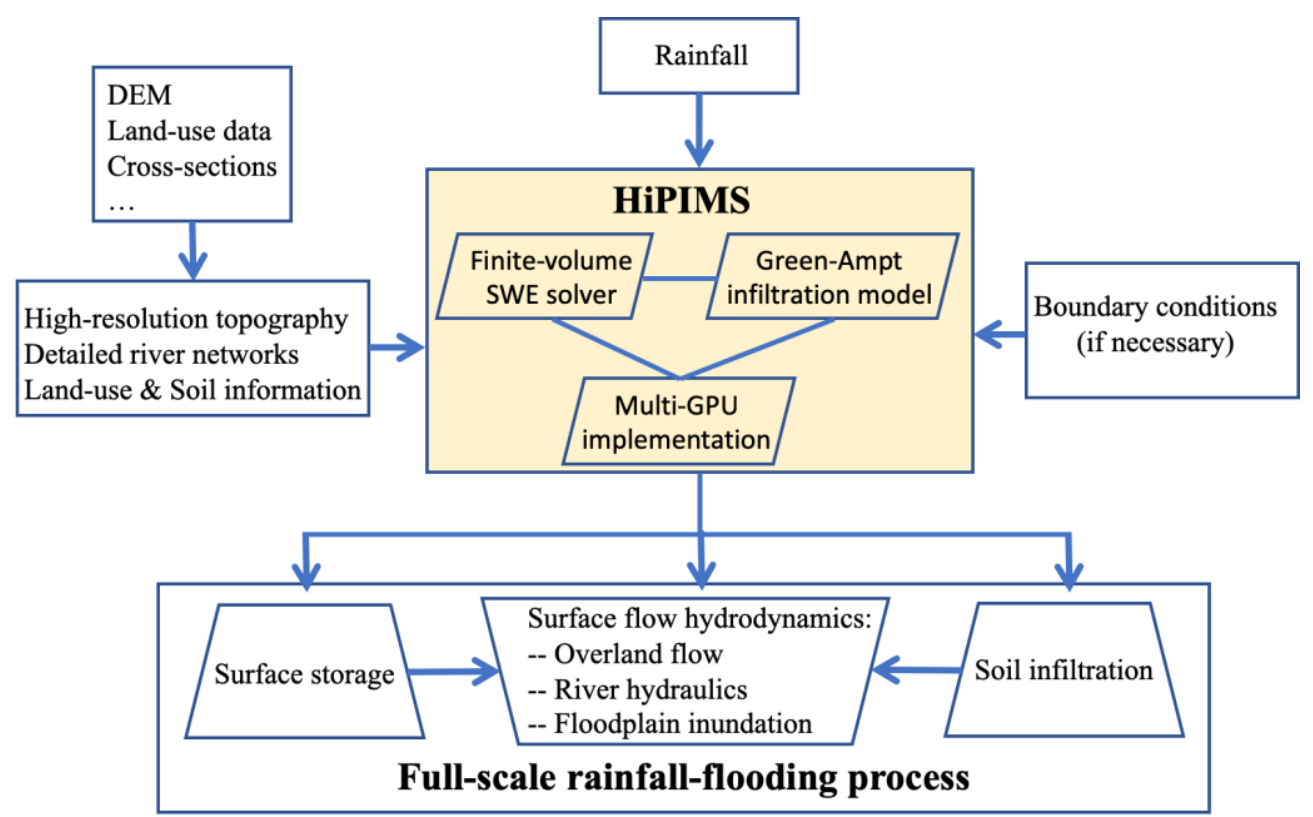

Figure 1 A new hydrodynamic modelling framework for predicting full-scale fluvial flooding induced by intense rainfall.
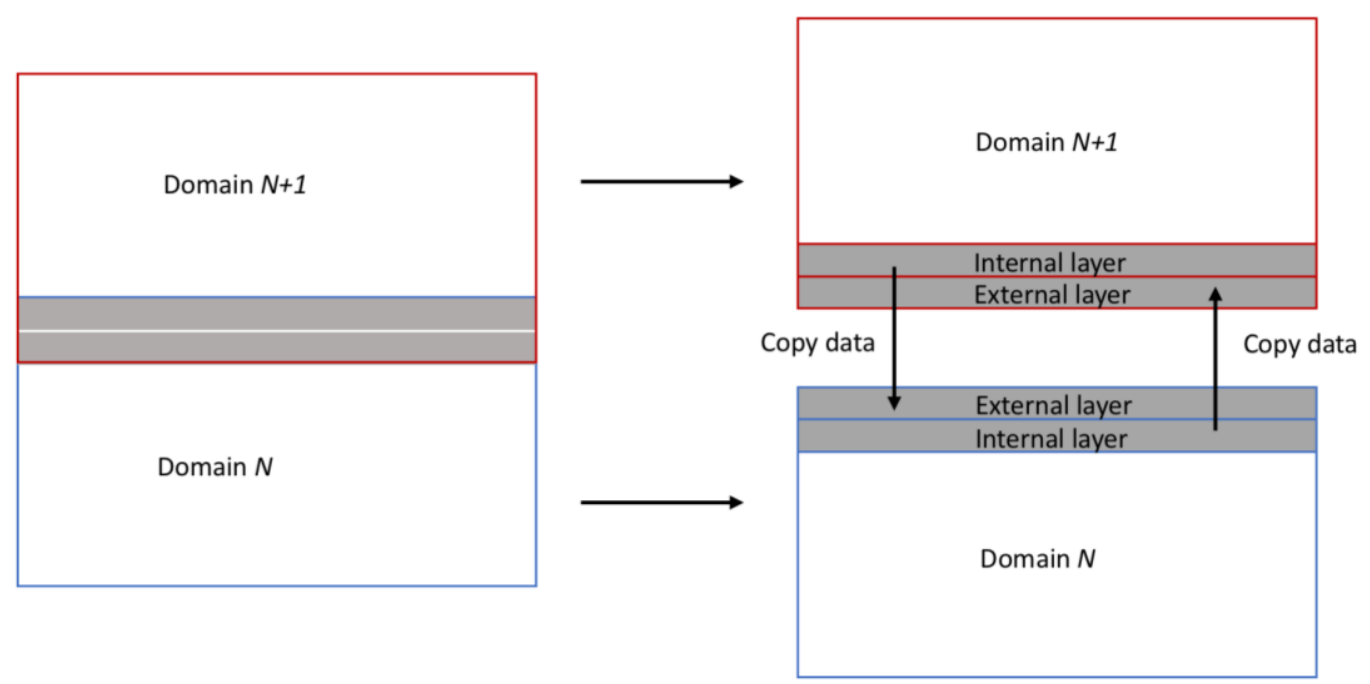

Figure 2 Domain decomposition for multi-GPU computing. 


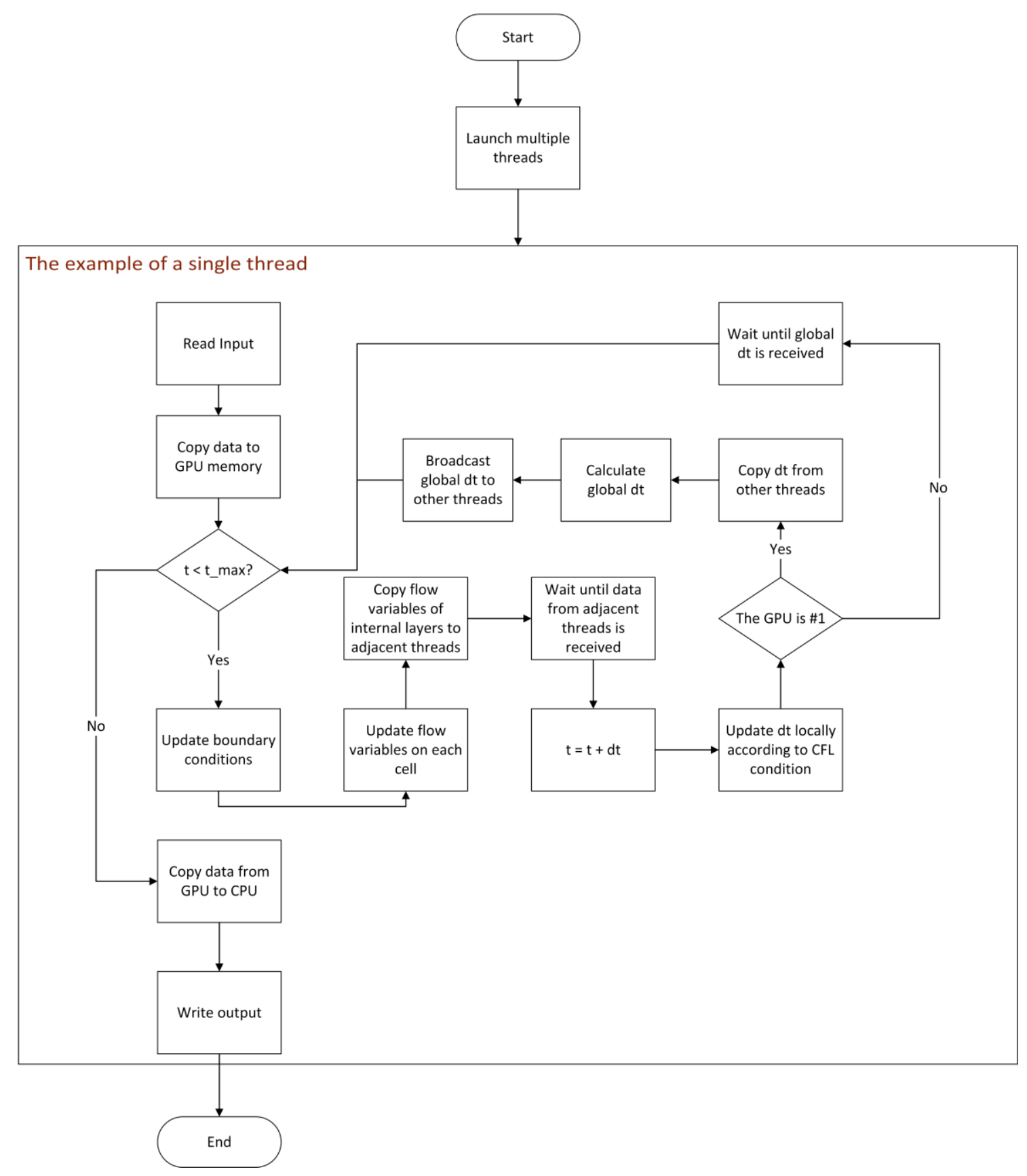

Figure 3 The procedure of implementing a multi-threading approach for multi-GPU computing using domain decomposition. 


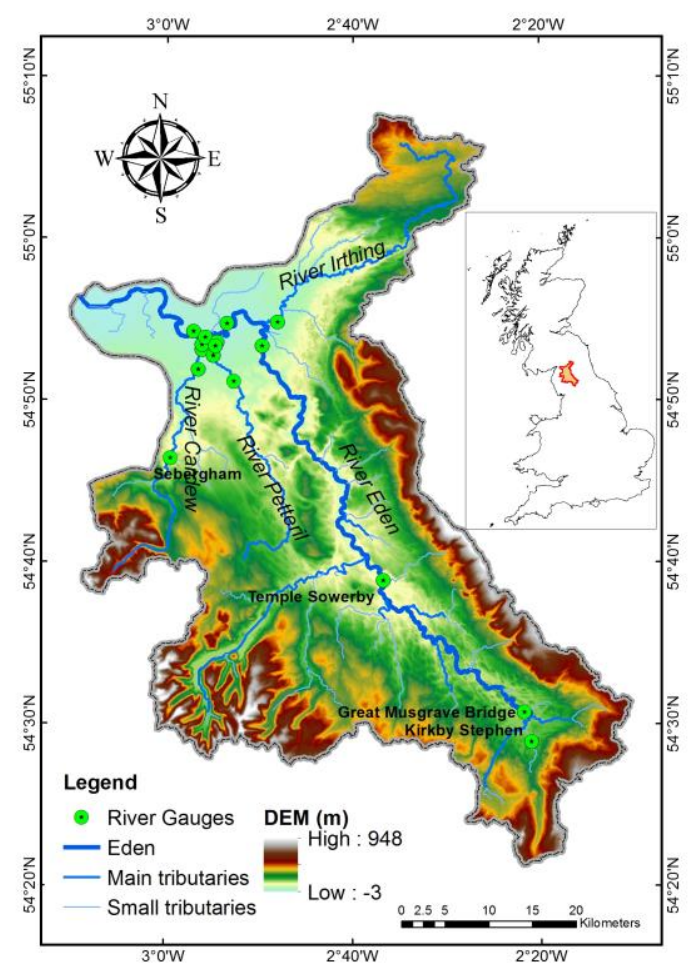

(a)

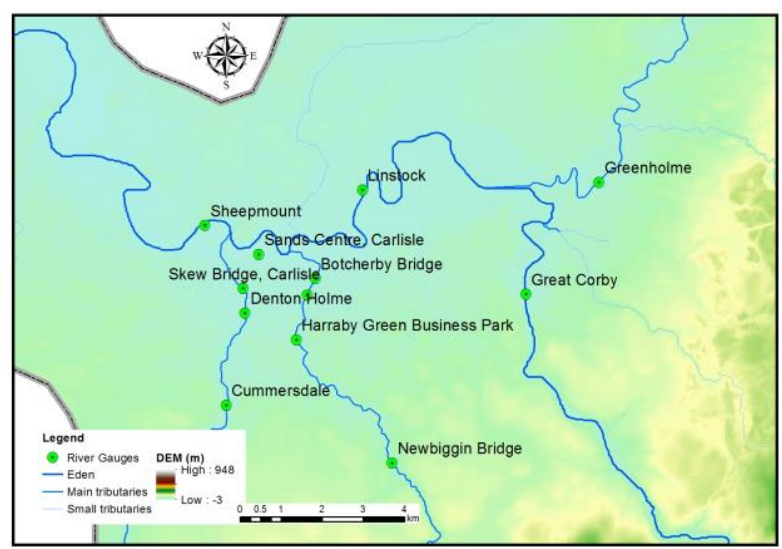

(b)

Figure 4 The maps of the Eden catchment: (a) the entire catchment; (b) downstream region near to Carlisle. 


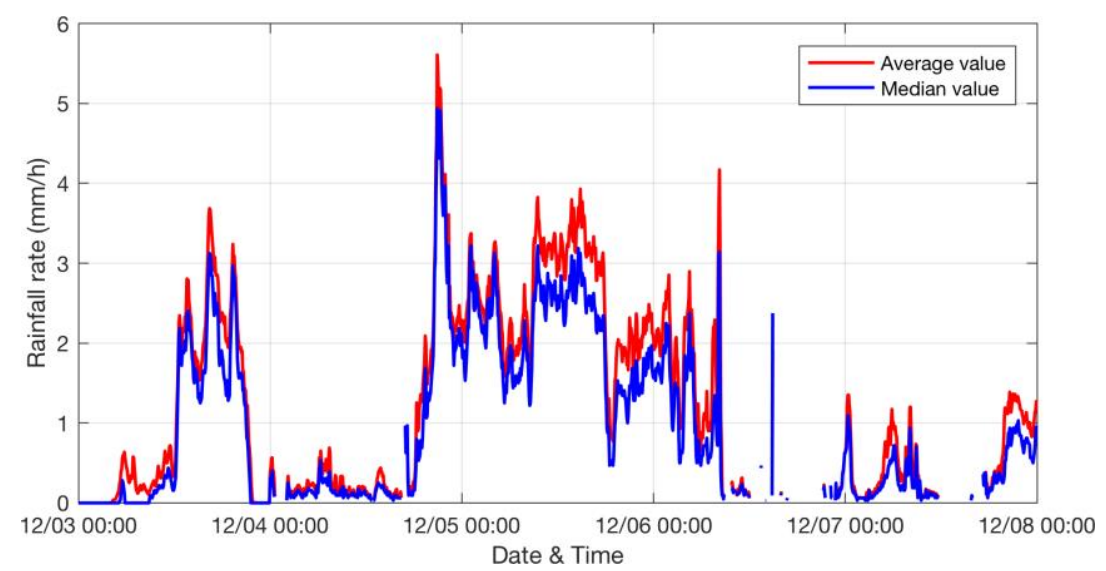

Figure 5 Time series of the mean rainfall intensity over the Eden catchment.

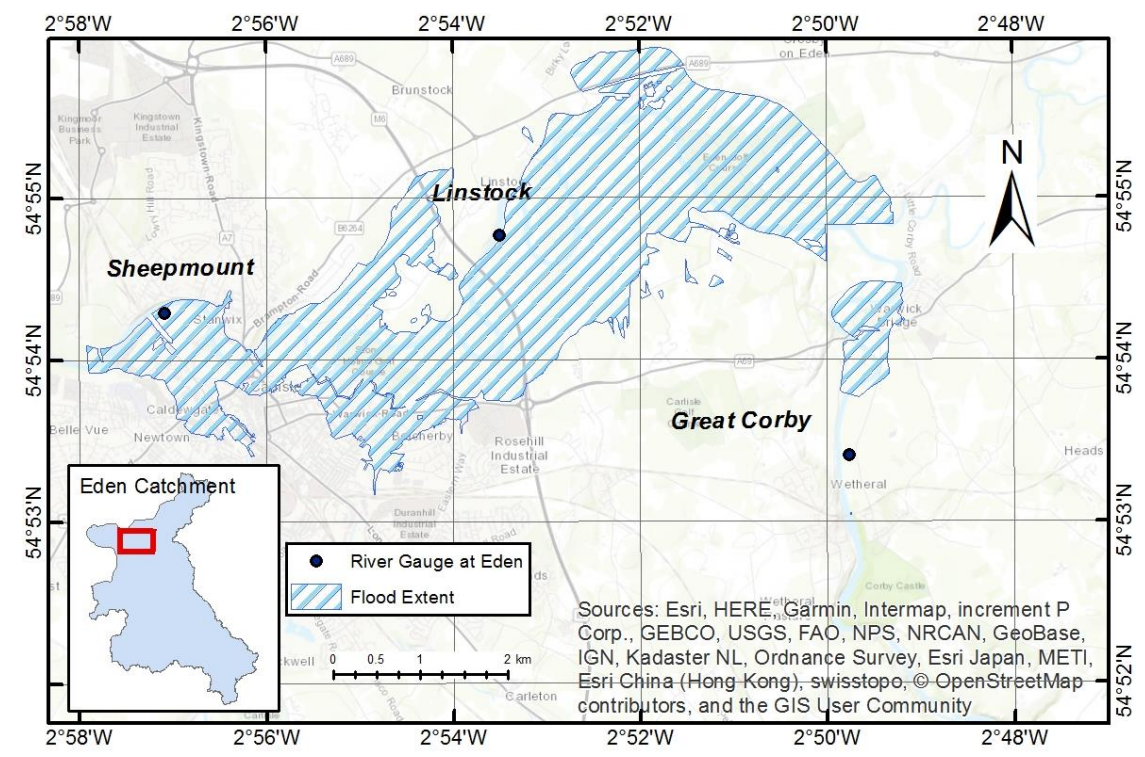

Figure 6 Post-event surveyed inundation area in Carlisle. 


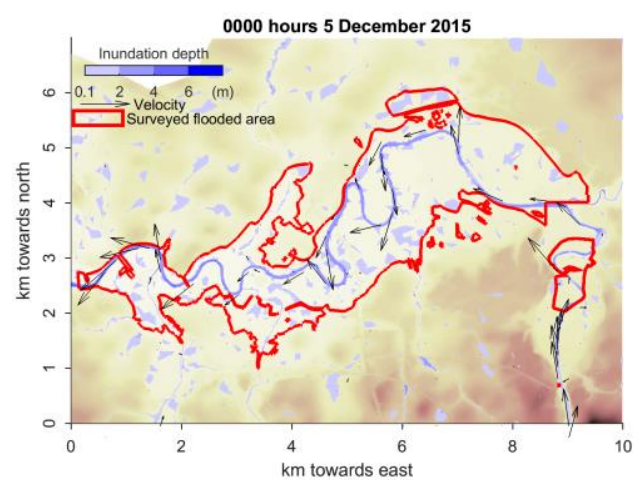

(a)

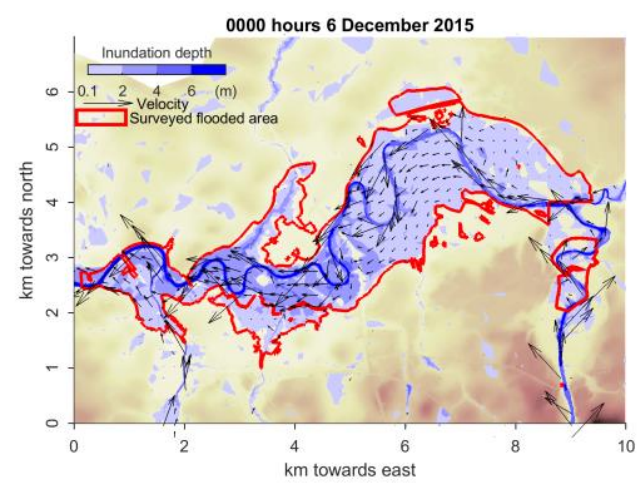

(c)

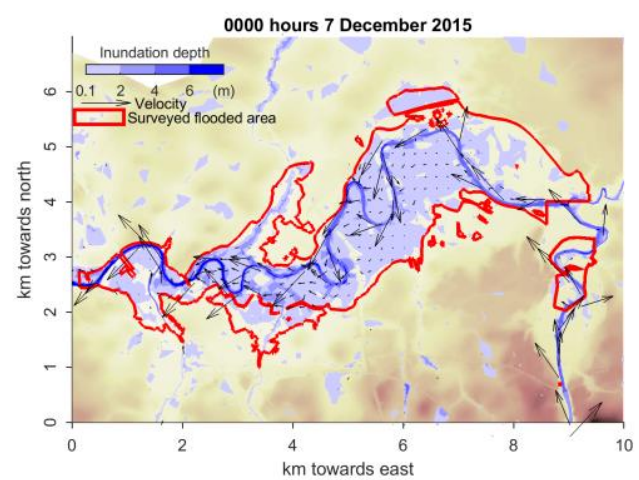

(e)

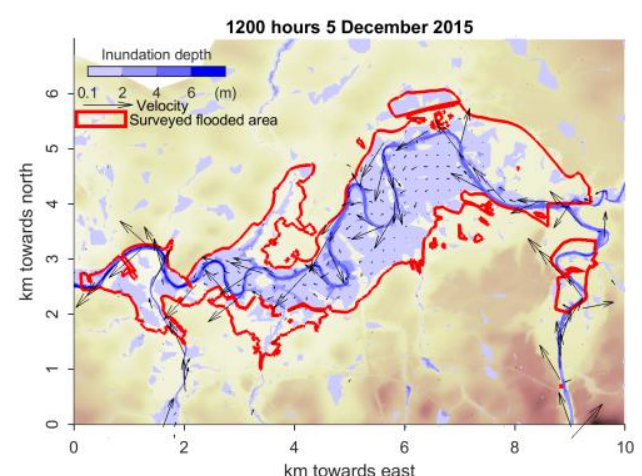

(b)

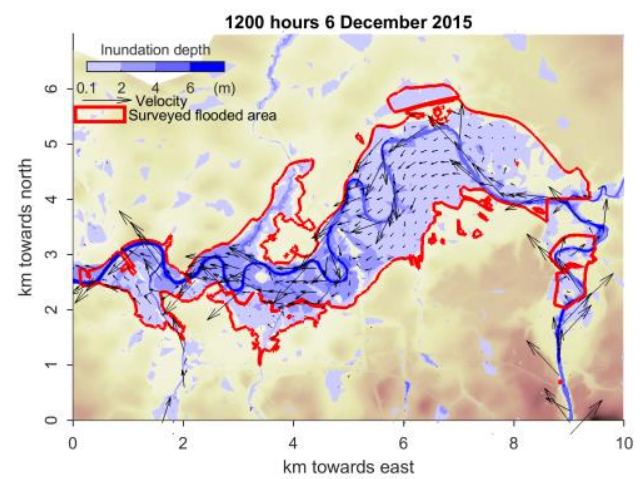

(d)

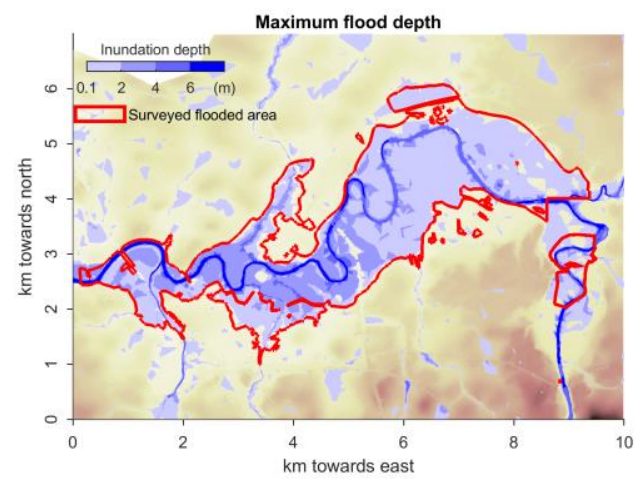

(f)

Figure 7 Simulated inundation and velocity maps in Carlisle: (a) $t=12 \mathrm{hrs}$; (b) $t=24 \mathrm{hrs}$; (c) $t=36 \mathrm{hrs}$; (d) $t=$ $48 \mathrm{hrs}$; (e) $t=60 \mathrm{hrs}$; (f) the maximum inundation map. 


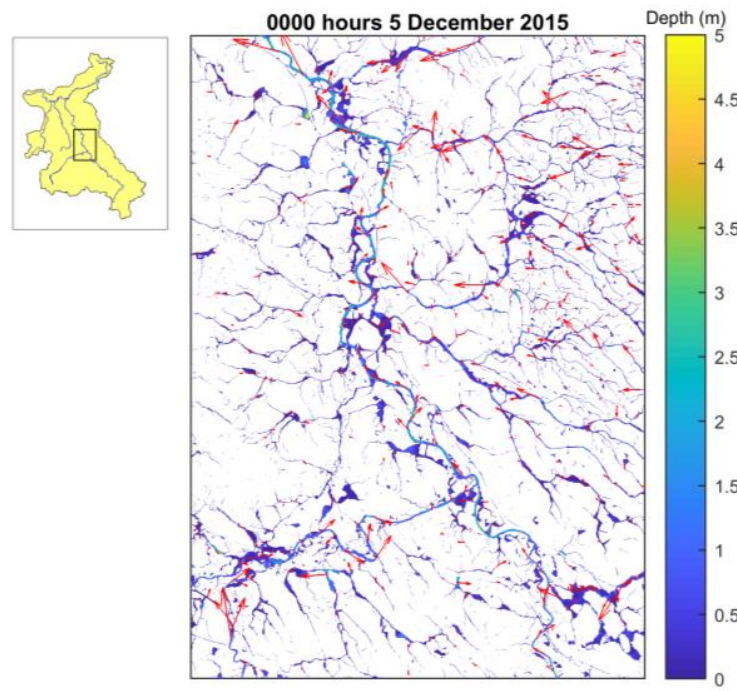

(a)

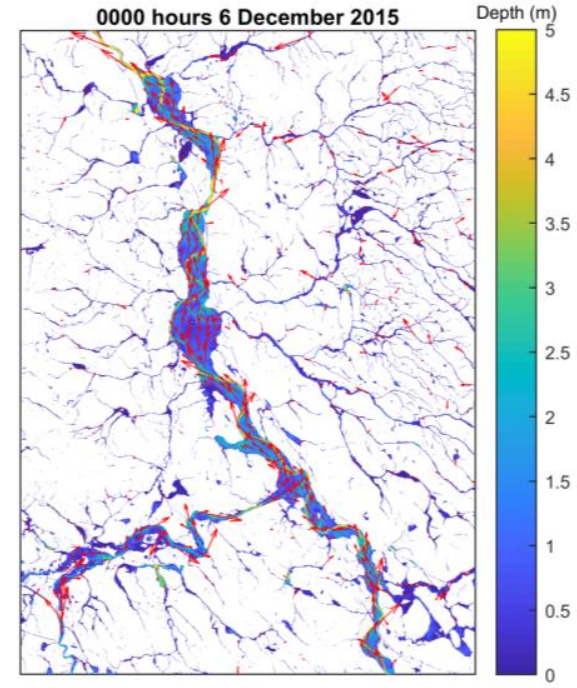

(b)

Figure 8 Simulated inundation and velocity maps for the midstream section of River Eden: (a) $t=12 \mathrm{hrs}$; (b) $t=$ $36 \mathrm{hrs}$.

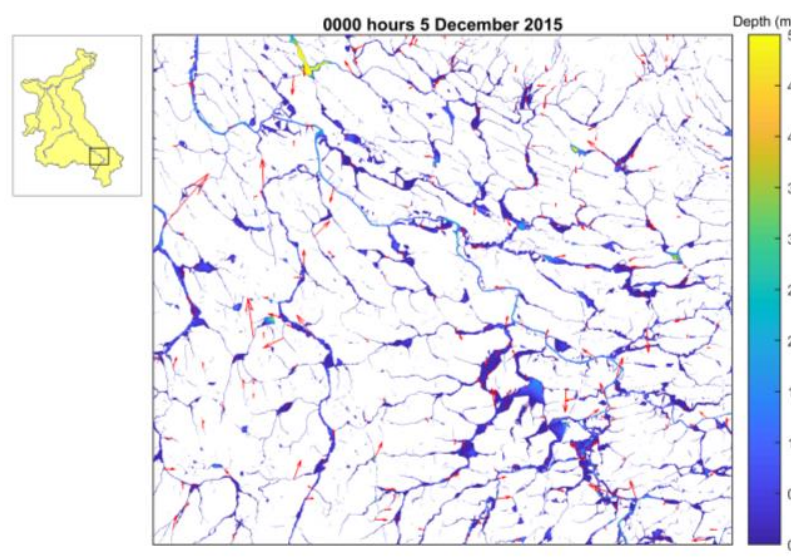

(a)

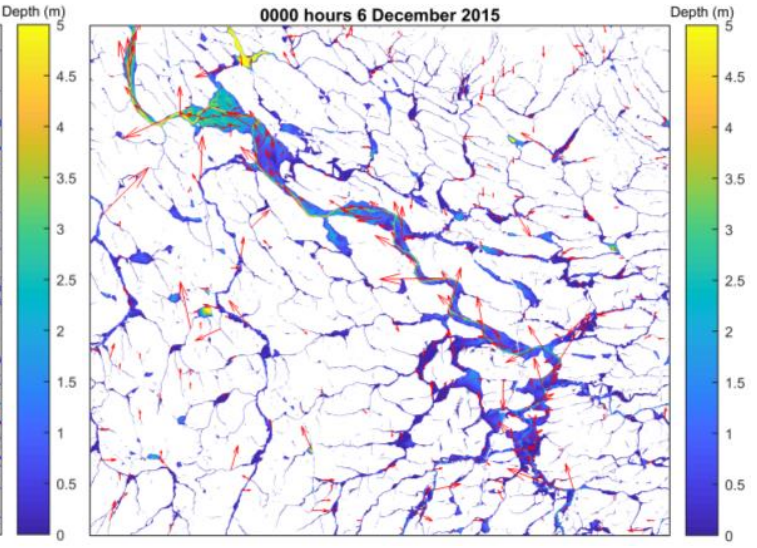

(b)

Figure 9 Simulated inundation and velocity maps for the upstream section of River Eden: (a) $t=12 \mathrm{hrs}$; (b) $t=$ $36 \mathrm{hrs}$. 

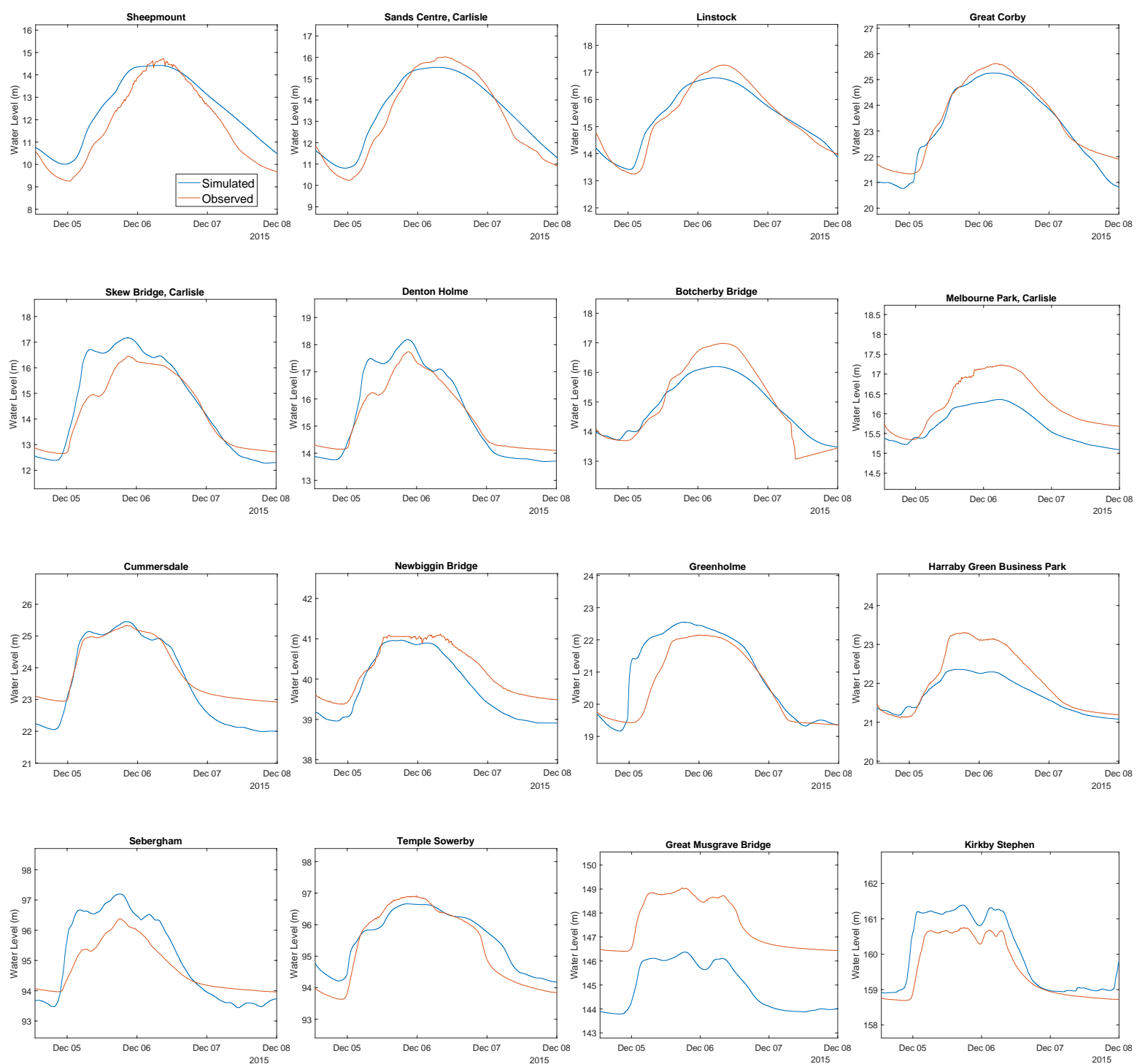

Figure 10 Simulated and observed water levels at different river gauges. 


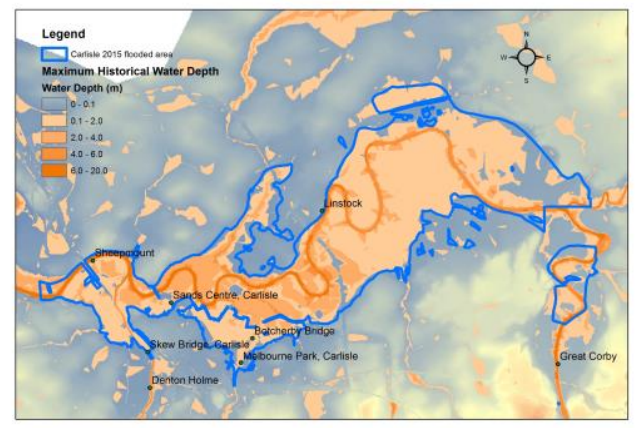

(a)

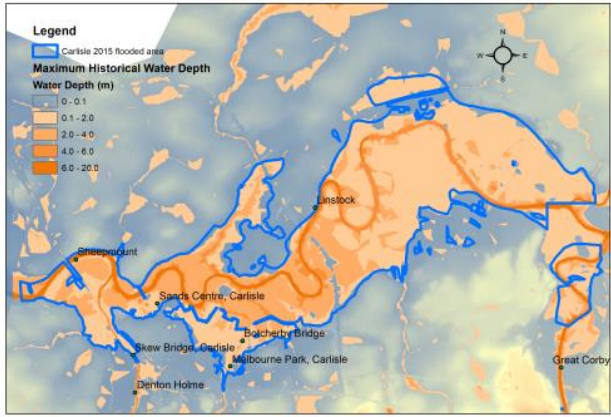

(c)

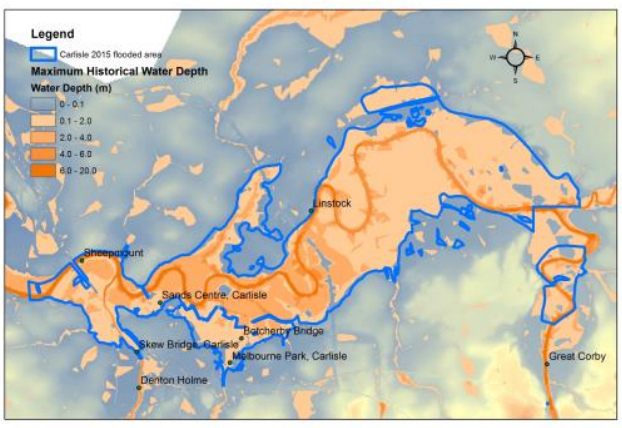

(b)

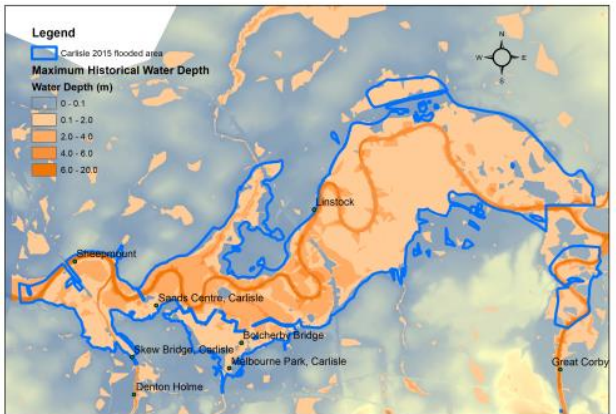

(d)

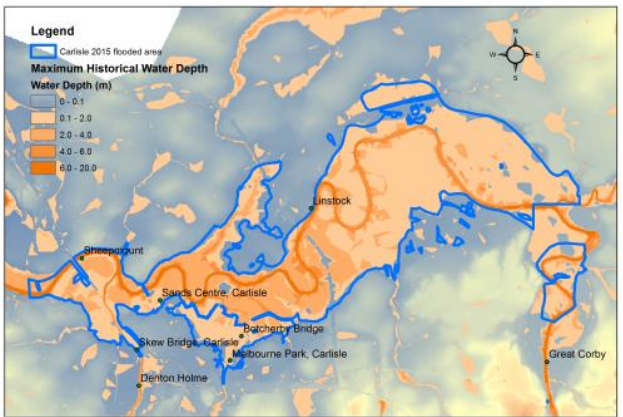

(e)

Figure 11 Maximum inundation predicted with different Manning coefficients: (a) $n_{l}=0.075 \mathrm{sm}^{-1 / 3}, n_{2}=0.035$ $\mathrm{sm}^{-1 / 3}$; (b) $n_{1}=0.075 \mathrm{sm}^{-1 / 3}, n_{2}=0.055 \mathrm{sm}^{-1 / 3}$; (c) $n_{1}=0.075 \mathrm{sm}^{-1 / 3}, n_{2}=0.075 \mathrm{sm}^{-1 / 3}$;(d) $n_{1}=0.055 \mathrm{sm}^{-1 / 3}, n_{2}=$ $0.055 \mathrm{sm}^{-1 / 3} ;$ (e) $n_{1}=0.095 \mathrm{sm}^{-1 / 3}, n_{2}=0.055 \mathrm{sm}^{-1 / 3}$. 

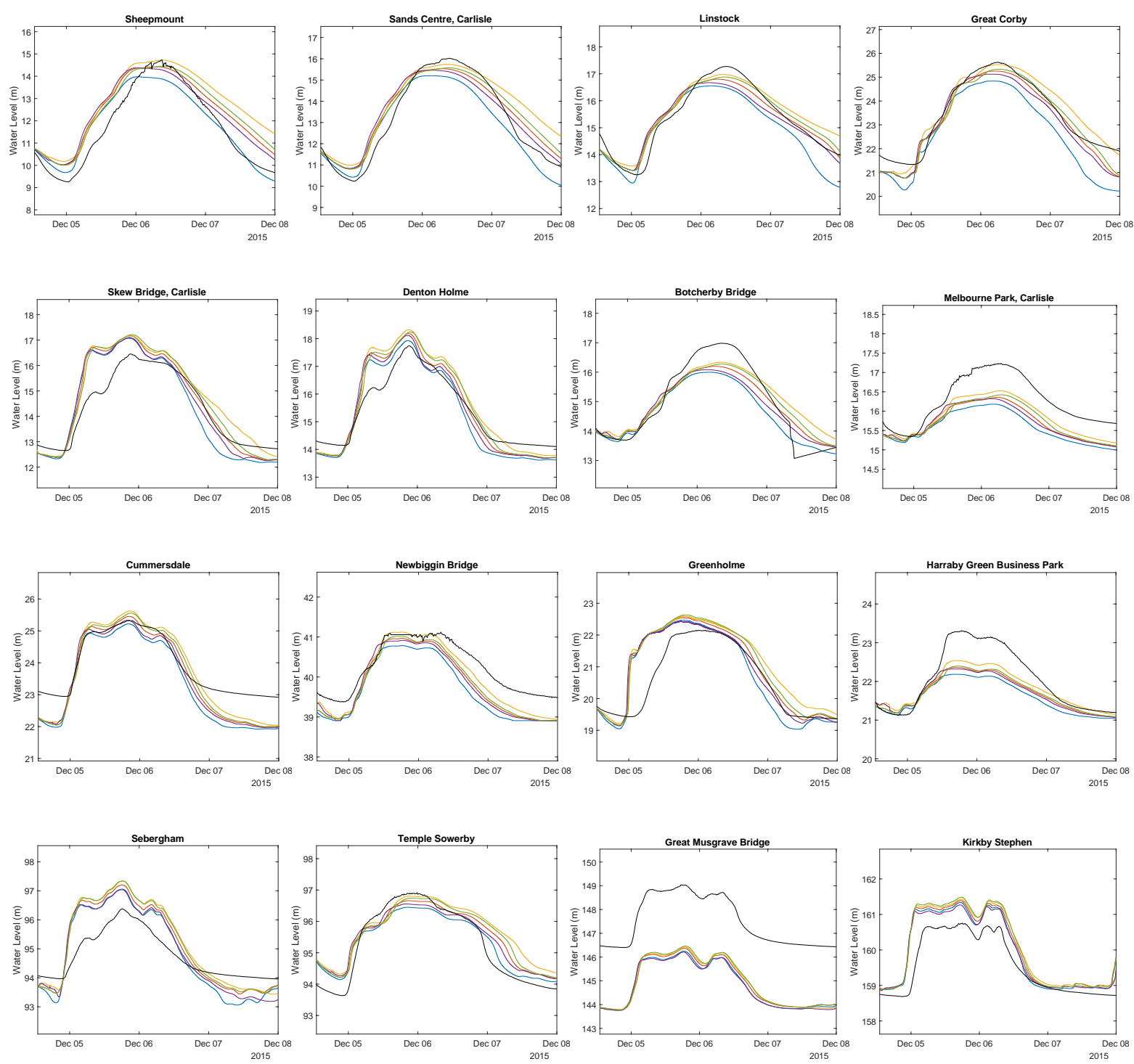

Legend
$\square \mathrm{n}_{1}=0.075, \mathrm{n}_{2}=0.035-\mathrm{n}_{1}=0.055, \mathrm{n}_{2}=0.055$
$\mathrm{n}_{1}=0.075, \mathrm{n}_{2}=0.055-\mathrm{n}_{1}=0.095, \mathrm{n}_{2}=0.055$
$\mathrm{n}_{1}=0.075, \mathrm{n}_{2}=0.075-$ Observed

Figure 12 Water levels at different river gauges, predicted by using different Manning coefficients. 


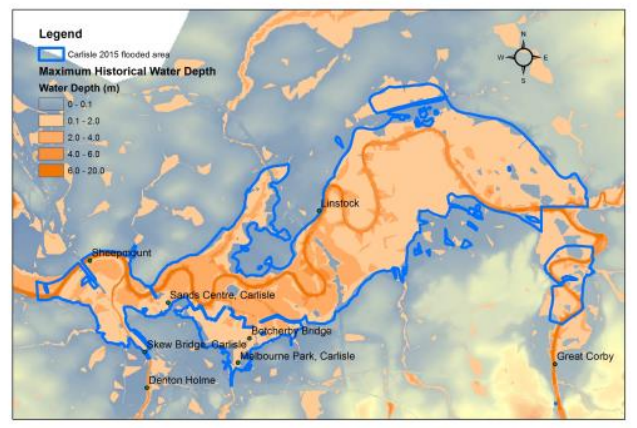

(a)

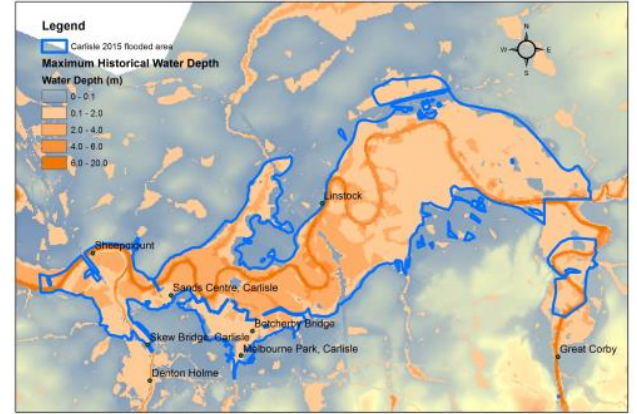

(c)

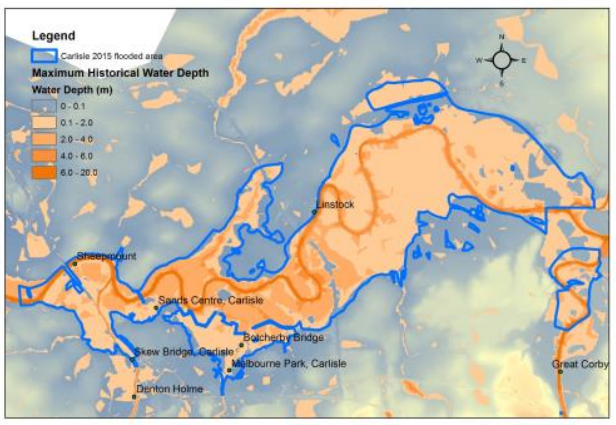

(b)

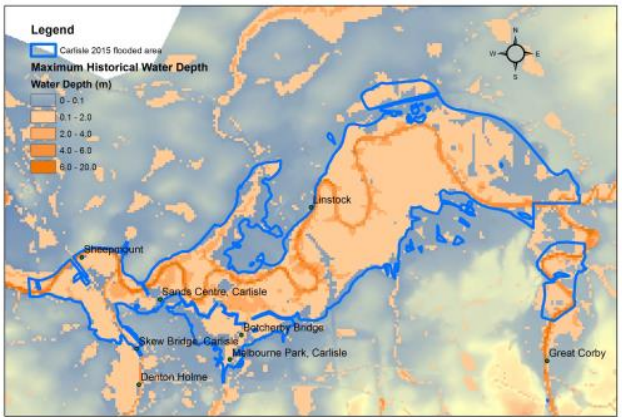

(d)

Figure 13 Maximum flood extents predicted on different DEMs: (a) 5 m; (b) 10 m; (c) 20 m; (d) 40 m. 


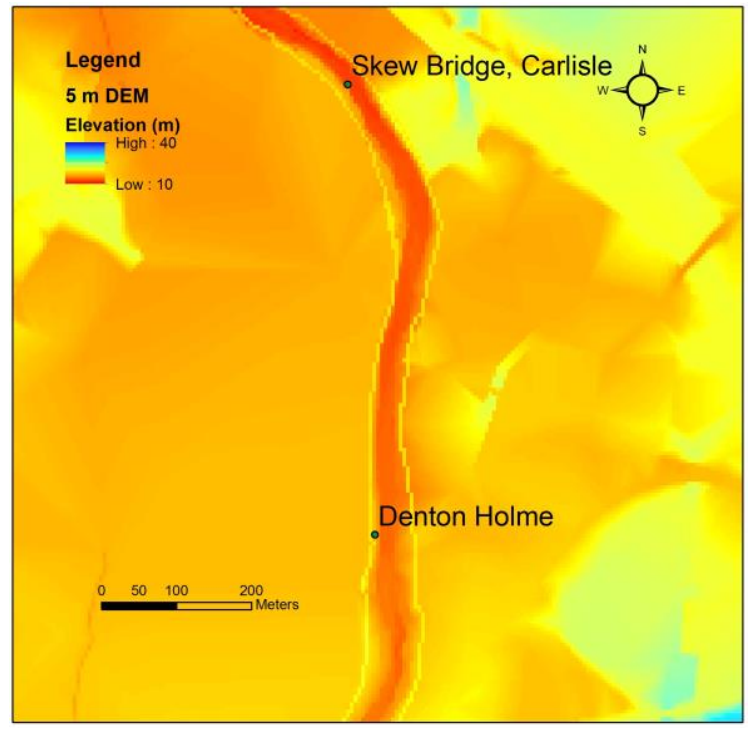

(a)

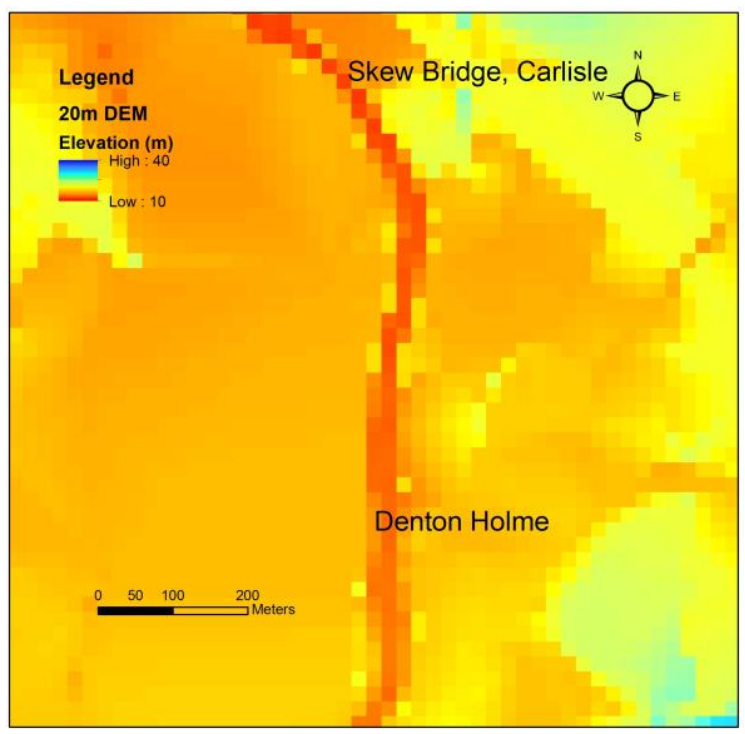

(c)

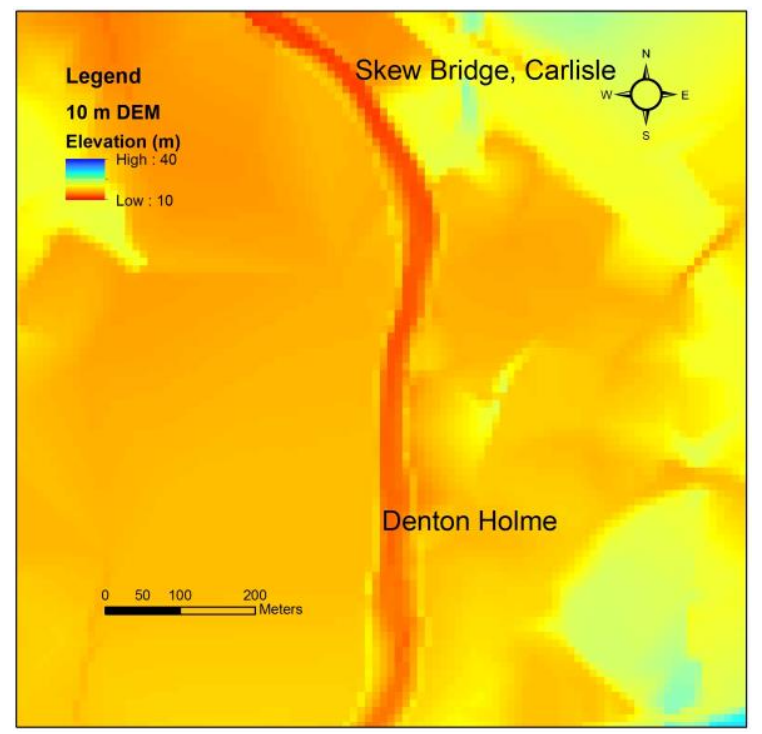

(b)

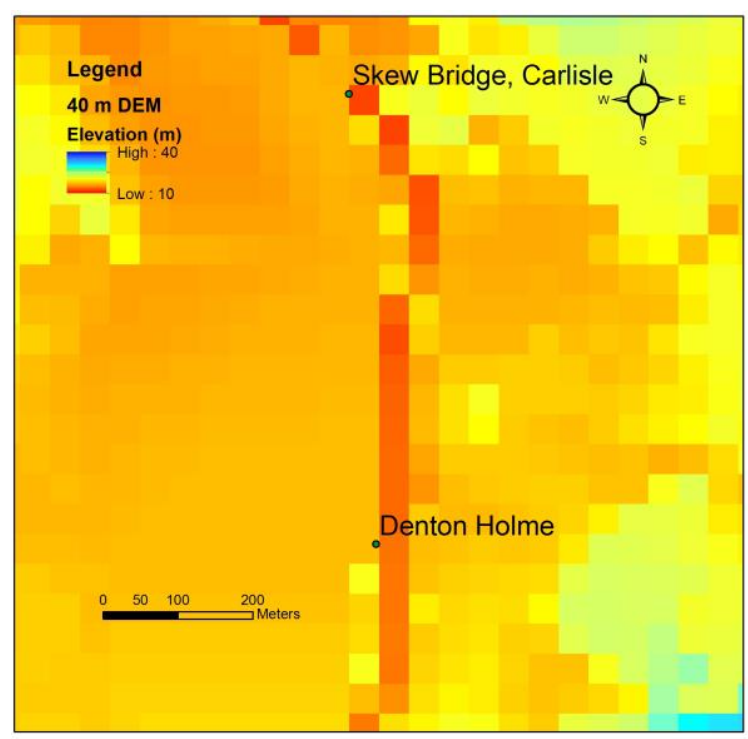

(d)

Figure 14 River geometries represented by the DEMs at different resolutions: (a) $5 \mathrm{~m}$; (b) $10 \mathrm{~m}$; (c) 20 m; (d) 40 $\mathrm{m}$. 

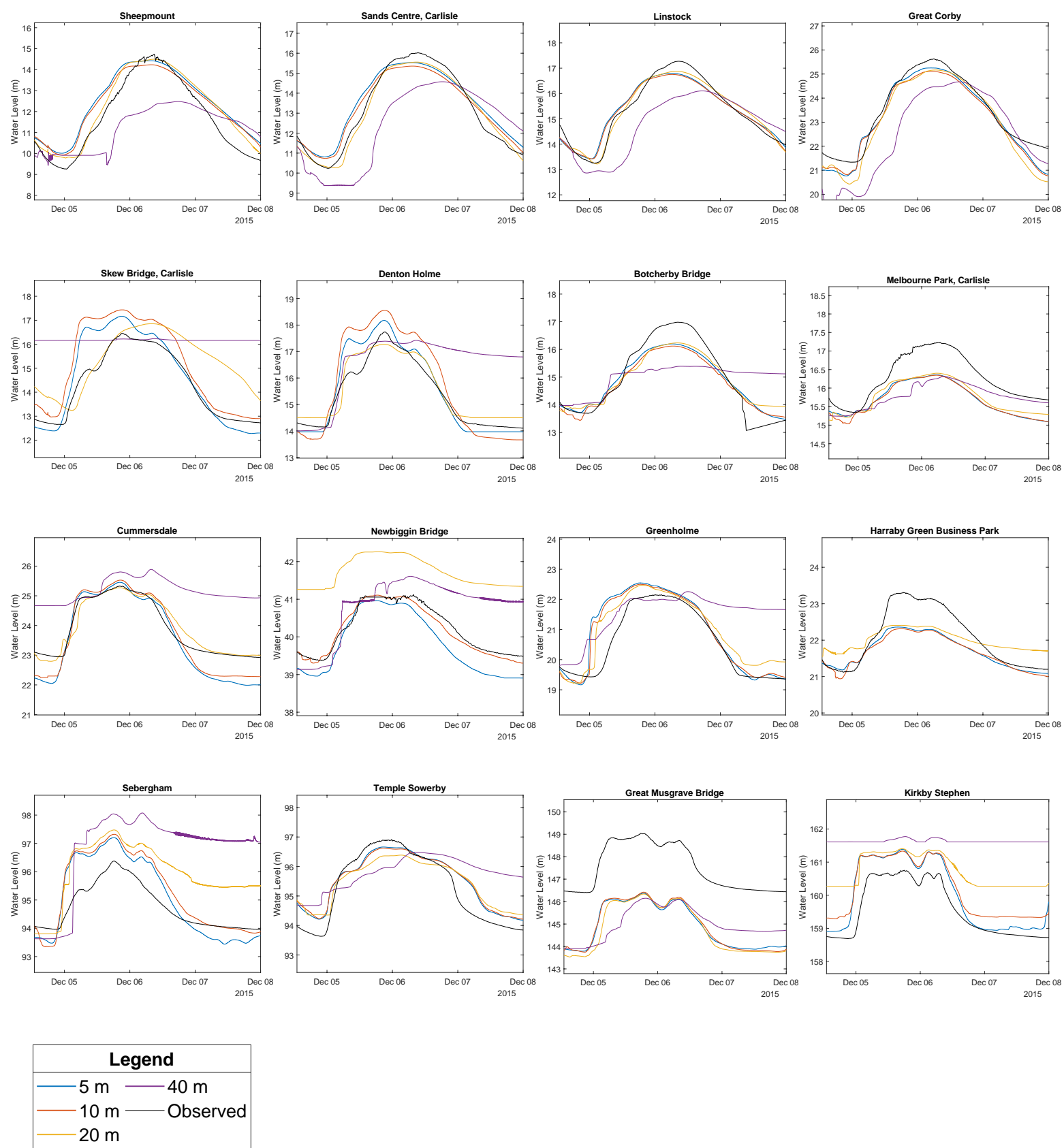

Figure 15 Time histories of water level predicted by simulations at different spatial resolutions. 
Table 1 Model parameters used in the simulations.

\begin{tabular}{cccc}
\hline Simulation No. & Resolution $(\mathrm{m})$ & $\begin{array}{c}\text { Floodplain and hillslope } \\
\text { Manning coefficient }\left(\mathrm{sm}^{-}\right.\end{array}$ & $\begin{array}{c}\text { River channel Manning } \\
\text { coefficient }\left(\mathrm{sm}^{-1 / 3}\right)\end{array}$ \\
\hline 1 & 5 & 0.075 & 0.055 \\
2 & 5 & 0.075 & 0.035 \\
3 & 5 & 0.075 & 0.075 \\
4 & 5 & 0.095 & 0.055 \\
5 & 5 & 0.055 & 0.055 \\
6 & 10 & 0.075 & 0.055 \\
7 & 20 & 0.075 & 0.055 \\
\hline & 40 & 0.075 & 0.055 \\
\hline
\end{tabular}

Table 2 Groups of the river gauges

Group names

Downstream of the Eden River

Upstream of the Eden River

Downstream of the tributaries

Upstream of the tributaries
Gauge names

Sheepmount; Sands Center,

Carlisle; Linstock; Great Corby

Temple Sowerby;

Kirkby Stephen

Skew Bridge, Carlisle; Denton Holme; Botcherby

Bridge; Melbourne Park, Carlisle; Cummersdale;

Green Holme; Harraby Green Business Park

Newbiggin Bridge;

Sebergham 
Table 3 The Nash-Sutcliffe coefficients calculated for different simulations.

\begin{tabular}{|c|c|c|c|c|c|c|c|c|c|}
\hline $\begin{array}{l}\text { Gauge } \\
\text { No. }\end{array}$ & Gauge Names & 1 & 2 & 3 & 4 & 5 & 6 & 7 & 8 \\
\hline 1 & Sheepmount & 0.79 & 0.90 & 0.58 & 0.76 & 0.81 & 0.73 & 0.61 & 0.40 \\
\hline 2 & Sands Centre, Carlisle & 0.92 & 0.87 & 0.81 & 0.91 & 0.91 & 0.90 & 0.83 & 0.30 \\
\hline 3 & Linstock & 0.93 & 0.75 & 0.90 & 0.94 & 0.89 & 0.93 & 0.88 & 0.38 \\
\hline 4 & Great Corby & 0.92 & 0.61 & 0.92 & 0.93 & 0.89 & 0.95 & 0.88 & 0.19 \\
\hline 5 & Skew Bridge, Carlisle & 0.75 & 0.68 & 0.70 & 0.74 & 0.74 & 0.42 & -0.21 & -1.70 \\
\hline 6 & Denton Holme & 0.85 & 0.87 & 0.76 & 0.83 & 0.81 & 0.49 & 0.84 & -0.72 \\
\hline 7 & Botcherby Bridge & 0.86 & 0.72 & 0.87 & 0.88 & 0.79 & 0.86 & 0.81 & 0.42 \\
\hline 8 & Melbourne Park, Carlisle & 0.01 & -0.46 & 0.41 & 0.16 & -0.06 & 0.16 & 0.47 & 0.07 \\
\hline 9 & Cummersdale & 0.61 & 0.45 & 0.67 & 0.62 & 0.58 & 0.74 & 0.77 & -1.46 \\
\hline 10 & Newbiggin Bridge & 0.46 & 0.11 & 0.71 & 0.52 & 0.38 & 0.97 & -5.02 & -0.70 \\
\hline 11 & Greenholme & 0.61 & 0.58 & 0.54 & 0.59 & 0.61 & 0.64 & 0.47 & -0.27 \\
\hline 12 & Harraby Green Business Park & 0.58 & 0.39 & 0.73 & 0.61 & 0.54 & 0.62 & 0.62 & -62.27 \\
\hline 13 & Sebergham & 0.11 & 0.10 & -0.08 & -0.04 & 0.16 & -0.18 & -2.55 & -7.77 \\
\hline 14 & Temple Sowerby & 0.85 & 0.90 & 0.72 & 0.80 & 0.86 & 0.77 & 0.60 & 0.13 \\
\hline 15 & Great Musgrave Bridge & -5.30 & -5.76 & -5.23 & -5.08 & -5.91 & -5.03 & -5.38 & -5.27 \\
\hline 16 & Kirkby Stephen & 0.55 & 0.62 & 0.49 & 0.46 & 0.65 & 0.32 & -1.33 & -6.32 \\
\hline N/A & $\begin{array}{l}\text { Mean of downstream of the } \\
\text { Eden River }\end{array}$ & 0.89 & 0.78 & 0.80 & 0.89 & 0.87 & 0.88 & 0.80 & 0.32 \\
\hline N/A & $\begin{array}{l}\text { Mean of upstream of the Eden } \\
\text { River }\end{array}$ & 0.70 & 0.76 & 0.61 & 0.63 & 0.76 & 0.54 & -0.36 & -3.09 \\
\hline N/A & $\begin{array}{l}\text { Mean of downstream of the } \\
\text { tributaries }\end{array}$ & 0.61 & 0.46 & 0.67 & 0.63 & 0.57 & 0.56 & 0.54 & -9.42 \\
\hline N/A & $\begin{array}{l}\text { Mean of upstream of the } \\
\text { tributaries }\end{array}$ & 0.29 & 0.10 & 0.31 & 0.24 & 0.27 & 0.40 & -3.79 & -4.24 \\
\hline
\end{tabular}


Table 4 The Root Mean Square Errors (m) calculated for different simulations.

\begin{tabular}{|c|c|c|c|c|c|c|c|c|c|}
\hline $\begin{array}{l}\text { Gauge } \\
\text { No. }\end{array}$ & Simulation No. & 1 & 2 & 3 & 4 & 5 & 6 & 7 & 8 \\
\hline 1 & Sheepmount & 0.81 & 0.57 & 1.16 & 0.87 & 0.78 & 0.92 & 1.12 & 1.39 \\
\hline 2 & Sands Centre, Carlisle & 0.56 & 0.72 & 0.88 & 0.59 & 0.61 & 0.62 & 0.83 & 1.67 \\
\hline 3 & Linstock & 0.33 & 0.63 & 0.39 & 0.29 & 0.43 & 0.33 & 0.44 & 0.99 \\
\hline 4 & Great Corby & 0.41 & 0.93 & 0.43 & 0.38 & 0.49 & 0.32 & 0.53 & 1.35 \\
\hline 5 & Skew Bridge, Carlisle & 0.70 & 0.79 & 0.76 & 0.72 & 0.71 & 1.06 & 1.54 & 2.30 \\
\hline 6 & Denton Holme & 0.48 & 0.45 & 0.60 & 0.50 & 0.52 & 0.88 & 0.50 & 1.62 \\
\hline 7 & Botcherby Bridge & 0.45 & 0.64 & 0.43 & 0.41 & 0.55 & 0.46 & 0.52 & 0.92 \\
\hline 8 & Melbourne Park, Carlisle & 0.62 & 0.76 & 0.48 & 0.58 & 0.65 & 0.58 & 0.46 & 0.61 \\
\hline 9 & Cummersdale & 0.58 & 0.69 & 0.54 & 0.57 & 0.61 & 0.48 & 0.45 & 1.46 \\
\hline 10 & Newbiggin Bridge & 0.47 & 0.60 & 0.35 & 0.44 & 0.50 & 0.11 & 1.57 & 0.83 \\
\hline 11 & Greenholme & 0.69 & 0.72 & 0.75 & 0.71 & 0.69 & 0.66 & 0.81 & 1.25 \\
\hline 12 & Harraby Green Business Park & 0.51 & 0.62 & 0.41 & 0.50 & 0.53 & 0.49 & 0.49 & 6.30 \\
\hline 13 & Sebergham & 0.75 & 0.75 & 0.83 & 0.81 & 0.73 & 0.86 & 1.50 & 2.35 \\
\hline 14 & Temple Sowerby & 0.47 & 0.38 & 0.63 & 0.53 & 0.44 & 0.57 & 0.75 & 1.11 \\
\hline 15 & Great Musgrave Bridge & 2.59 & 2.68 & 2.57 & 2.54 & 2.71 & 2.53 & 2.60 & 2.58 \\
\hline 16 & Kirkby Stephen & 0.55 & 0.51 & 0.59 & 0.60 & 0.49 & 0.68 & 1.26 & 2.23 \\
\hline N/A & Mean of downstream of the Eden River & 0.53 & 0.71 & 0.71 & 0.54 & 0.58 & 0.55 & 0.73 & 1.35 \\
\hline N/A & Mean of upstream of the Eden River & 0.51 & 0.45 & 0.61 & 0.57 & 0.46 & 0.63 & 1.01 & 1.67 \\
\hline N/A & Mean of downstream of the tributaries & 0.58 & 0.67 & 0.57 & 0.57 & 0.61 & 0.66 & 0.68 & 2.07 \\
\hline N/A & Mean of upstream of the tributaries & 0.61 & 0.68 & 0.59 & 0.63 & 0.61 & 0.48 & 1.54 & 1.59 \\
\hline
\end{tabular}


Table 5 Runtimes required by the different simulations.

\begin{tabular}{ccccc}
\hline Resolution & Cells number & Device & Event duration & Runtime \\
\hline $5 \mathrm{~m}$ & 100 million & 8 Nvidia Tesla K80 & 96 hours & 37.5 hours \\
$10 \mathrm{~m}$ & 25 million & 8 Nvidia Tesla K80 & 96 hours & 4.5 hours \\
$20 \mathrm{~m}$ & 6.25 million & 8 Nvidia Tesla K80 & 96 hours & 1.17 hours \\
$40 \mathrm{~m}$ & 1.5625 million & 8 Nvidia Tesla K80 & 96 hours & 0.15 hours \\
\hline
\end{tabular}

